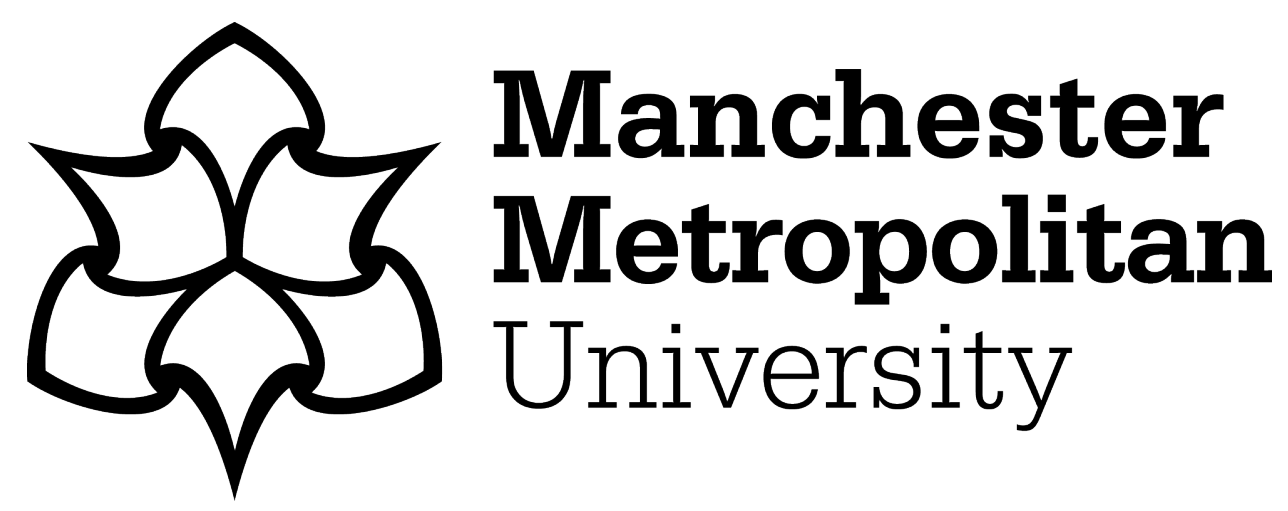

Salar, U, Nizamani, A, Arshad, F, Khan, KM, Fakhri, MI, Perveen, S, Ahmed, $\mathrm{N}$ and Choudhary, MI (2019) Bis-coumarins; non-cytotoxic selective urease inhibitors and antiglycation agents. Bioorganic Chemistry, 91. ISSN 00452068

Downloaded from: https://e-space.mmu.ac.uk/626692/

Version: Accepted Version

Publisher: Elsevier

DOI: https://doi.org/10.1016/j.bioorg.2019.103170

Usage rights: Creative Commons: Attribution-Noncommercial-No Derivative Works 4.0

Please cite the published version 


\title{
Bis-coumarins; non-cytotoxic selective urease inhibitors and antiglycation agents
}

\author{
Uzma Salar $^{\mathrm{a}, \mathrm{b}}$, Arsalan Nizamani ${ }^{\mathrm{a}}$, Fizza Arshad ${ }^{\mathrm{a}}$, Khalid Mohammed Khan ${ }^{\mathrm{a}, \mathrm{e}, *}$, \\ Muhammed Imran Fakhri ${ }^{\mathrm{a}}$, Shahnaz Perveen ${ }^{\mathrm{c}}$, Nessar Ahmed ${ }^{\mathrm{d}}$, M. Iqbal Choudhary ${ }^{\mathrm{a}, \mathrm{b}, \mathrm{f}}$ \\ ${ }^{a}$ H. E. J. Research Institute of Chemistry, International Center for Chemical and Biological Sciences, University of Karachi, Karachi 75270, Pakistan \\ ${ }^{\mathrm{b}}$ Dr. Panjwani Center for Molecular Medicine and Drug Research, International Center for Chemical and Biological Sciences, University of Karachi, Karachi 75270, \\ Pakistan \\ ${ }^{\mathrm{c}}$ PCSIR Laboratories Complex, Karachi, Shahrah-e-Dr. Salimuzzaman Siddiqui, Karachi 75280, Pakistan \\ ${ }^{\mathrm{d}}$ Centre for Biomedicine, School of Healthcare Science, Manchester Metropolitan University, Manchester M1 5GD, United Kingdom \\ ${ }^{\mathrm{e}}$ Department of Clinical Pharmacy, Institute for Research and Medical Consultations (IRMC), Imam Abdulrahman Bin Faisal University, P.O. Box 31441, Dammam, Saudi \\ Arabia \\ ${ }^{\mathrm{f}}$ Department of Biochemistry, King Abdulaziz University, Jeddah 214412, Saudi Arabia
}

A R T I C L E I N F O

\section{Keywords:}

Bis-coumarins

Urease

Glycation

Advanced glycation end products

Peptic ulcer

Diabetes

Non-cytotoxic

\begin{abstract}
A B S T R A C T
The current study is concerned with the identification of lead molecules based on the bis-coumarin scaffold having selective urease inhibitory and antiglycation activities. For that purpose, bis-coumarins (1-44) were synthesized and structurally characterized by different spectroscopic techniques. Eight derivatives 4, 8-10, 14, 17,34 , and 40 demonstrated urease inhibition in the range of $\mathrm{IC}_{50}=4.4 \pm 0.21-115.6 \pm 2.13 \mu \mathrm{M}$, as compared to standard thiourea $\left(\mathrm{IC}_{50}=21.3 \pm 1.3 \mu \mathrm{M}\right)$. Especially, compound 17 ( $\left.\mathrm{IC}_{50}=4.4 \pm 0.21 \mu \mathrm{M}\right)$ was found to be five-fold more potent than the standard. Kinetic studies were also performed on compound 17 in order to identify the mechanism of inhibition. Kinetic studies revealed that compound $\mathbf{1 7}$ is a competitive inhibitor. Antiglycation activity was evaluated using glycation of bovine serum albumin by methylglyoxal in vitro. Compounds $2,11-13,16,17,19-22,35,37$, and 42 showed good to moderate antiglycation activities with IC $_{50}$ values of 333.63-919.72 $\mu \mathrm{M}$, as compared to the standard rutin (IC ${ }_{50}=294.46 \pm 1.5 \mu \mathrm{M}$ ). Results of both assays showed that the compounds with urease inhibitory activity did not show any antiglycation potential, and vice versa. Only compound 17 showed dual inhibition potential. All compounds were also evaluated for cytotoxicity. Compounds 17, 19, and 37 showed a weak toxicity towards 3 T3 mouse fibroblast cell line. All other compounds were found to be non-cytotoxic. Urease inhibition is an approach to treat infections caused by ureolytic bacteria whereas inhibition of glycation of proteins is a strategy to avoid late diabetic complications. Therefore, these compounds may serve as leads for further research.
\end{abstract}

\section{Introduction}

Bis-coumarins are biologically active pharmacophores, initially isolated from natural sources $[1,2]$. Several biological activities are associated with bis-coumarins, such as $\alpha$-glucosidase [3], urease [4], nucleotide pyrophosphatases-1 [5], and DNA polymerase $\beta$-lyase inhibitory activities [6]. Bis-coumarins are also reported to possess anticoagulant, and hemorrhagic properties [7]. However, there is still a need to explore this class for a wide spectrum of pharmacological activities.

Urease (amidohydrolase EC 3.5.1.5) is a metalloenzyme, contains nickel in its active site. It catalyzes the hydrolysis of urea into carbon dioxide and ammonia $[8,9]$. This enzyme synthesizes by numerous plants, animals, bacteria, and other organisms [10]. Hyperactivity of urease is harmful to human and animal health, as well as for the agricultural sector. Urease is a key virulence in the pathogenesis of urolithiasis, urinary catheter encrustation, pyelonephritis, hepatic coma, and hepatic encephalopathy [11,12]. It also participates in the pathologies caused by ureolytic bacteria Helicobacter pylori (HP). It facilitates bacteria to survive in stomach at acidic $\mathrm{pH}$ during initial colonization. Therefore, it plays an important role in the pathologies of ulcers (gastric and peptic), and cancer [13-16]. In the agriculture

* Corresponding author at: H. E. J. Research Institute of Chemistry, International Center for Chemical and Biological Sciences, University of Karachi, Karachi 75270, Pakistan.

E-mail address: khalid.khan@iccs.edu (K.M. Khan). 
sector, hyperactivity of urease leads to considerable economic and environmental damage by liberating aberrantly large quantities of ammonia into the atmosphere, during the process of urea fertilization [17]. Therefore, it is important to develop strategies based on urease inhibition to solve the problems caused by urease producing bacteria.

Glycation is a non-enzymatic reaction in which reducing sugars nonenzymatically bind with the amino terminal of proteins via a nucleophilic addition reaction, ultimately giving rise to advanced glycation end products (AGEs). Haemoglobin, serum albumin, collagen, elastin, and crystalline are common proteins that undergo glycation. Changes in their structures and functions lead to different abnormalities such as atherosclerosis, neuropathy, diabetic retinopathy, diabetic nephropathy, etc. This process is cumulatively called glycation stress $[18,19]$. In this process, reactive intermediates such as methylglyoxal (MG) are more prone to bind with amino groups as compared to their carbohydrate precursors. Eighty percent $(80 \%)$ of blood proteins is serum albumin, which is more likely to be glycated [20]. As a result of complex rearrangements, substitution, and addition reactions of glycated proteins, AGEs are produced in the body which change the functions of proteins, and accumulate with time in different tissues [21-23]. Many late diabetic complications, such as retinopathy, nephropathy, cataracts, atherosclerosis, and osteoporosis are due to the glycation of vital proteins, and accumulation of AGEs [24]. The inhibition of glycation process plays a pivotal role in the prevention of many late diabetic complications. Therefore, it is important to find inhibitors for glycation.

Bis-coumarins have not yet been reported for their antiglycation activity. Fig. 1 showed that chromone ring, a positional isomer of coumarin, is the main scaffold of rutin which encouraged us to evaluate the compounds 1-44 for their antiglycation activity. Furthermore, we have previously reported bis-coumarins for urease inhibitory activity [4]. New members of this series were thus evaluated to identify more potent urease inhibitors [Fig. 1]. In brief, forty-four derivatives were synthesized and evaluated for their urease inhibitory, and antiglycation activities. After knowing the selective potential of compounds, cytotoxicity was also checked. To the best of our knowledge, except compounds $\mathbf{6}, \mathbf{1 4}, \mathbf{1 6}, \mathbf{1 7}, \mathbf{1 9}, \mathbf{2 0}, \mathbf{2 3 - 2 6 , 2 8}$, and 30-32 [25-29], the rest of the compounds were identified as new.

\section{Results and discussion}

\subsection{Chemistry}

Bis-coumarin derivatives 1-44 were synthesized by reacting 6fluoro-4-hydroxy, 4-hydroxy, and 6-chloro-4-hydroxy coumarins with a variety of benzaldehydes in the presence of tetraethylammonium bromide (TEAB) as a catalyst. Reactions were performed in distilled water (Scheme 1) and checked periodically by TLC analysis. Precipitates of products were obtained in good yields (Table 1). Compounds were structurally identified by various spectroscopic analyses such as ${ }^{1} \mathrm{H}$ - and ${ }^{13} \mathrm{C}$ NMR as well as FAB-, ESI-, and HRESI-MS.

\subsection{Characteristic spectral features of representative compound 21}

Structure elucidation of a new compound $\mathbf{2 1}$ is presented here as an example. ${ }^{1} \mathrm{H}$ - and ${ }^{13} \mathrm{C}$ NMR spectra of compound 21 were recorded in DMSO- $d_{6}$. Characteristic signal of methine proton resonated as a singlet at $\delta_{\mathrm{H}} 5.60$, also confirmed the formation of the bis-coumarin scaffold. Amongst the protons of coumarin nucleus, $\mathrm{H}-7$ and $\mathrm{H}-7^{\prime}$ resonated at $\delta_{\mathrm{H}}$ 7.53 as triplet, and showed ortho coupling (t, $J_{7,6 / 7^{\prime}, 6^{\prime}}=J_{7,8}$ $7^{\prime}, 8^{\prime}=6.9 \mathrm{~Hz}$ ) with adjacent protons, $\mathrm{H}-6 / \mathrm{H}-6^{\prime}$ and $\mathrm{H}-8 / \mathrm{H}-8^{\prime}$. Similarly, H-6 and H-6' appeared as a triplet at $\delta_{\mathrm{H}} 7.26$, and also showed ortho coupling ( $\mathrm{t}, J_{6,5 / 6^{\prime}, 5^{\prime}}=J_{6,7 / 6^{\prime}, 7^{\prime}}=7.5 \mathrm{~Hz}$ ) with neighbouring protons. $\mathrm{H}$ 5 and $\mathrm{H}^{-5^{\prime}}$ appeared as the most downfield signal at $\delta_{\mathrm{H}} 7.82$ with ortho coupling (d, $J_{5,6 / 5^{\prime}, 6^{\prime}}=6.3 \mathrm{~Hz}$ ) with the adjacent H-6 and H-6'. H-8 and $\mathrm{H}-8^{\prime}$ appeared at $\delta_{\mathrm{H}} 7.27$, ortho coupled (d, $J_{8,7 / 8^{\prime}, 7^{\prime}}=8.1 \mathrm{~Hz}$ ) with H-7 and $\mathrm{H}^{-} \mathbf{7}^{\prime}$. H-2" and $\mathrm{H}-6^{\prime \prime}$ of ring $\mathrm{R}_{2}$ resonated as a broad singlet at $\delta_{\mathrm{H}}$ 7.12 (Fig. 2).

Total 16 signals of carbon (eleven methine and fourteen quarternary carbons) appeared in ${ }^{13} \mathrm{C}$ NMR broad-band decoupled spectrum (DMSO- $d_{6}$ ). Most downfield signal of C-2 and C-2', which are the quaternary carbons of lactone moiety, appeared at $\delta_{\mathrm{C}}$ 167.2. Similarly, other quaternary C-10/C-10', and C-4/C- $4^{\prime}$ resonated at $\delta_{\mathrm{C}} 164.2$ and 152.4 as the downfield signals due to the adjacent electronegative oxygen atom. An upfield characteristic signal resonated at $\delta_{\mathrm{C}} 35.0$, corresponding to the methine $\mathrm{CH}$ carbon.

The structure of compound $\mathbf{2 1}$ was further confirmed with the help

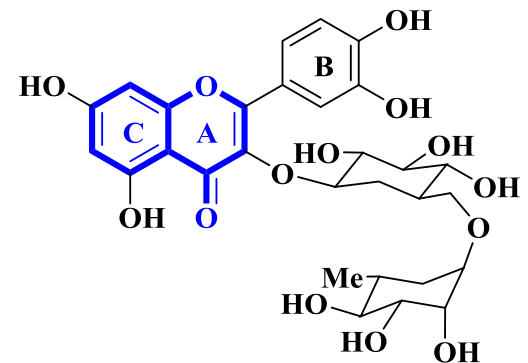

Rutin (Standard) for Antiglycation Assay $\left(\mathrm{IC}_{50}=\mathbf{2 9 4 . 4 6} \pm 1.5 \mu \mathrm{M}\right)$<smiles>[R]C(c1c(O)c2ccccc2oc1=O)c1c(O)c2ccccc2oc1=O</smiles>

IC $_{50}=15.06-91.35 \mu \mathrm{M}[4]$<smiles>O=c1cc(O)c2ccccc2o1</smiles>

Not active [4]

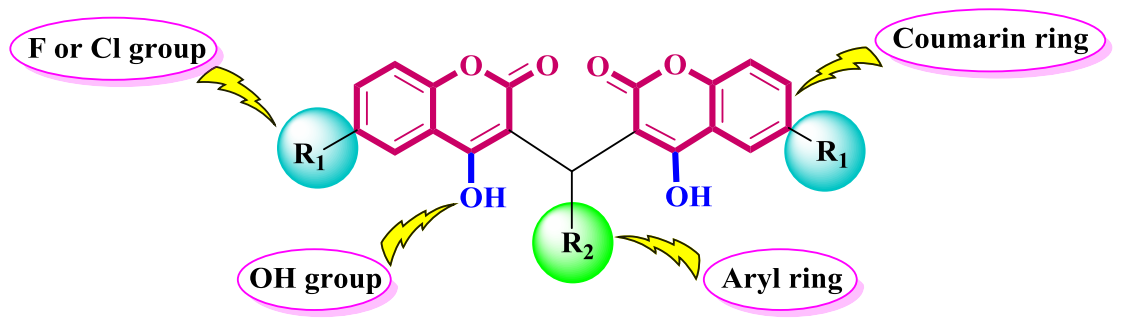

Urease Inhibitory Activity (UIA) $\Rightarrow \mathrm{IC}_{50}=4.4-115.6 \mu \mathrm{M}$

Antiglycation Activity (AGA) $\Rightarrow \mathrm{IC}_{\mathbf{5 0}}=\mathbf{3 3 3 . 6 3 - 9 1 9 . 7 2} \mu \mathrm{M}$

Non-Cytotoxic

Fig. 1. Structural similarity between rutin and bis-coumarins $1-44$ as a rationale of the current study. 
$\overbrace{O_{O H}^{O}}^{O}$

$\begin{array}{ll}\mathbf{1 - 1 5} & \mathrm{R}_{1}=\mathrm{F} \\ \mathbf{1 6 - 3 1} & \mathrm{R}_{1}=\mathrm{H} \\ \mathbf{3 2 - 4 4} & \mathrm{R}_{1}=\mathrm{Cl}\end{array}$

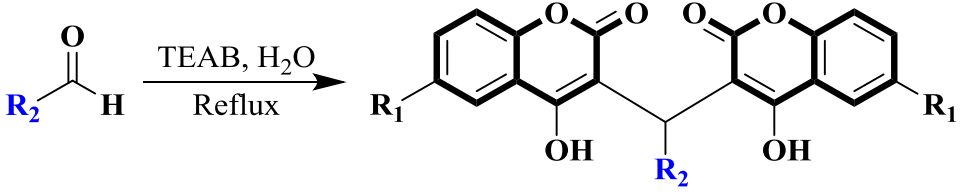

1-44
Scheme 1. Synthesis of bis-coumarin derivatives $1-44$. of FAB (Neg.)-MS, ESI-MS, and HRESI-MS. FAB (Neg.)-MS of compound 21 displayed the peaks at $m / z=584[\mathrm{M}-\mathrm{H}]^{-1} 586[\mathrm{M}+2-\mathrm{H}]^{-1}$ and $588[\mathrm{M}+4-\mathrm{H}]^{-1}$ which indicated the presence of two bromine atoms. Similarly, ESI-MS of compound 21 displayed the $[\mathrm{M}+\mathrm{H}]^{+},[\mathrm{M}$ $+2+\mathrm{H}]^{+}$, and $[\mathrm{M}+4+\mathrm{H}]^{+}$at $m / z 585,587$, and 589, respectively. HR-(ESI)MS showed the $[\mathrm{M}+\mathrm{H}]^{+}$at $m / z 584.9208$, corresponding to the formula $\mathrm{C}_{25} \mathrm{H}_{15} \mathrm{Br}_{2} \mathrm{O}_{7}$ Calcd (584.9184). The UV spectrum of compound 21 showed absorption at $298 \mathrm{~nm}$, characteristic of coumarin moiety. The structure of new compound 21 was thus deduced unambiguously.

\subsection{Bioactivities in vitro}

Forty-four bis-coumarin derivatives were evaluated for urease inhibitory, and antiglycation activities (Table 1). Eight compounds 4, 8-10, 14, 17, 34, and 40, showed a good to moderate urease inhibitory activity in the range of $\mathrm{IC}_{50}=4.4 \pm 0.21-115.6 \pm 2.13 \mu \mathrm{M}$, as compared to standard thiourea $\left(\mathrm{IC}_{50}=21.3 \pm 1.3 \mu \mathrm{M}\right)$. Whereas, compounds 2, 11-13, 16, 17, 19, 20-22, 35, 37, and 42 demonstrated good to moderate antiglycation activities in the range of IC $_{50}=333.63-919.72 \mu \mathrm{M}$, as compared to standard rutin $\left(\mathrm{IC}_{50}=294.46 \pm 1.5 \mu \mathrm{M}\right)$. Bis-coumarins have never been reported before for its antiglycation activity. It is worth mentioning that the compounds showed selective activity in both assays. Bis-coumarins which showed urease inhibitory activity did not give the antiglycation potential, and vice versa. All compounds were also checked for their cytotoxicity and largely found to be non-cytotoxic.

\subsection{Structure-activity relationship (SAR)}

All structural features of bis-coumarin derivatives such as coumarin ring, substitutions on coumarin rings $\left(\mathrm{R}_{1}\right)$, and aryl ring $\left(\mathrm{R}_{2}\right)$ apparently playing their role in the inhibitory activity, and variation in the activity can be attributed to the different substitution pattern on coumarin, and aryl rings (Fig. 3).

Results presented in Table 1 indicate that almost all compounds selectively exhibited their potential in both assays, and found to be nontoxic as well.

Bis-coumarins 1-44 were divided into three categories in order to understand the structure-activity pattern. In category " $A$ ", fluoro groups are present at C-6 and C-6' of bis-coumarin i.e. 1-15. Category " $\mathrm{B}$ " compounds 16-31 has no substitution on both coumarin rings, and category "C" has chloro groups at C-6 and C-6' i.e. compounds 32-44.

In category "A", non-cytotoxic compound 8 $\left(\mathrm{IC}_{50}=30.3 \pm 1.01 \mu \mathrm{M}\right)$ with $3^{\prime \prime}$-benzyloxy and 4 "-methoxy substitutions showed comparable urease inhibitory activity with the standard thiourea $\left(\mathrm{IC}_{50}=21.3 \pm 1.3 \mu \mathrm{M}\right.$ ), and did not show any antiglycation potential. The good urease inhibitory activity of the compound 8 could be due to $\pi-\pi$ stacking of the benzyloxy group with the active site of urease enzyme. Activity of compound $\mathbf{8}$ was compared with the activity of non-cytotoxic compound 14 $\left(\mathrm{IC}_{50}=187.3 \pm 1.75 \mu \mathrm{M}\right)$ which has a bromo group instead of a benzyloxy at C-3", showed six times less urease inhibitory activity. This indicated the involvement of benzyloxy in the inhibitory activity. Similarly, compound $\mathbf{1 4}$ did not show any antiglycation potential. It is worth mentioning that both compounds 8 and 14 showed selective activity towards the urease, as well as being non-cytotoxic. Other compounds with different positional combination of methoxy and bromo groups such as compounds $\mathbf{3}, \mathbf{5}$, and $\mathbf{1 5}$, did not show any urease inhibitory and antiglycation activities. However, all three were found to be non-cytotoxic. The activity of compound $\mathbf{3}$ can be compared with compound 2 ( $\left.\mathrm{IC}_{50}=378.03 \pm 0.75 \mu \mathrm{M}\right)$ which has a fluoro group, instead of a bromo at C-2", showed an antiglycation potential comparable to the standard rutin $\left(\mathrm{IC}_{50}=294.46 \pm 1.5 \mu \mathrm{M}\right)$. It showed that fluoro group on aryl ring plays an important role in the antiglycation activity (Fig. 4).

In the same category " $\mathrm{A}$ ", compounds with the halogen substitutions $(4,9$, and 10), and the compounds with combinations of halogen and hydroxy groups (11 and 12), showed a good selectivity and non-cytotoxicity. For example, compound $4\left(\mathrm{IC}_{50}=87.0 \pm 0.88 \mu \mathrm{M}\right)$ with 2 ", 4 "-dichloro substitutions showed a selective urease inhibitory activity, and no antiglycation activity. The two chloro groups on aryl ring might form some polar interactions with the active site of the urease enzyme. Similarly, another compound $9\left(\mathrm{IC}_{50}=79.8 \pm 1.01 \mu \mathrm{M}\right)$ with a 4"-trifluoromethyl group, also showed urease inhibitory activity but no antiglycation activity. This might be that trifluoromethyl group establish polar interaction with the active site of urease enzyme. However, its positional isomer 10 ( $\left.\mathrm{IC}_{50}=193.7 \pm 0.66 \mu \mathrm{M}\right)$ with a $4^{\prime \prime}$ trifluoromethyl group, showed two times lower activity. It showed that C-3" substitution is not favourable for urease inhibition (Fig. 5).

Compounds with the combination of halogen and hydroxy, such as $\mathbf{1 1}(\mathrm{OH}$ and $\mathrm{F}$ para to each other) and $\mathbf{1 2}(\mathrm{OH}$ and $\mathrm{Cl}$ para to each other) showed no urease inhibition, however, they did show antiglycation activity. Similarly, compound $13\left(\mathrm{IC}_{50}=443.64 \pm 0.57 \mu \mathrm{M}\right)$ with 2 ", 4 "-dihydroxy substitutions also showed antiglycation potential (Fig. 6). Thus hydroxy group is apparently playing an important role in the antiglycation activity. Phenolic $\mathrm{OH}$ known to have radical scavenging activity through phenolic $\mathrm{OH}$ groups, along with other structural features which may contribute to the inhibition of protein glycation.

Involvement of hydroxy groups in the antiglycation activity was further deduced by examining antiglycation activity pattern of compounds $\mathbf{1 6}$ $\left(\mathrm{IC}_{50}=351.85 \pm 3.56 \mu \mathrm{M}\right), \quad 17 \quad\left(\mathrm{IC}_{50}=374.45 \pm 1.21 \mu \mathrm{M}\right)$, and 20 $\left(\mathrm{IC}_{50}=434.71 \pm 2.73 \mu \mathrm{M}\right)$ belong to category "B". Compound 16 $\left(\mathrm{IC}_{50}=351.85 \pm 3.56 \mu \mathrm{M}\right)$, having a 2,3-dihydroxy substitution, was selectively active against glycation but no urease inhibitory activity. The antiglycation activity of compound $\mathbf{1 6}$ can be compared with compound 20 ( $\left.\mathrm{IC}_{50}=434.71 \pm 2.73 \mu \mathrm{M}\right)$ which has a 2,4-dihydroxy group, instead of 2,3-dihydroxy, and showed lower antiglycation activity. This shows that the positions of $\mathrm{OH}$ substitution also plays a role in the activity. However, incorporation of one or more hydroxy group in compound $\mathbf{1 7}$ $\left(\mathrm{IC}_{50}=374.45 \pm 1.21 \mu \mathrm{M}\right)$ enhanced the antiglycation potential to a considerable level. In addition, compound $\mathbf{1 7}$ was found to be a potent urease inhibitor, with five times more activity than the standard thiourea $\left(\mathrm{IC}_{50}=21.3 \pm 1.3 \mu \mathrm{M}\right)$. Interestingly, this is the only compound which showed dual inhibitory activity against urease and glycation (Fig. 7).

Other compounds with the halogen substitutions such as compound 22 with $3^{\prime \prime}, 5^{\prime \prime}$-dichloro substitutions, showed an antiglycation activity $\left(\mathrm{IC}_{50}=428.84 \pm 2.44 \mu \mathrm{M}\right)$ but no urease inhibitory activity. Compounds having the combination of halogen $(\mathrm{Cl}$ and $\mathrm{Br})$ with the hydroxy group such as $\mathbf{1 9}$ and 21, did not display any urease inhibition, however, both compounds $19\left(\mathrm{IC}_{50}=432.58 \pm 0.76 \mu \mathrm{M}\right)$ and 21 $\left(\mathrm{IC}_{50}=397.07 \pm 2.21 \mu \mathrm{M}\right.$ ) showed antiglycation activity (Fig. 8). All 
Table 1

In vitro urease inhibitory activity, antiglycation activity, and cytotoxicity of bis-coumarins (1-44).

\begin{tabular}{|c|c|c|c|c|}
\hline Compounds & $\mathrm{R}_{2}$ & $\begin{array}{l}\text { Urease Inhibitory Activity } \\
\mathrm{IC}_{50} \pm \mathrm{SEM}^{\mathrm{a}}\end{array}$ & $\begin{array}{l}\text { Antiglycation Activity } \\
\text { IC }_{50} \pm \text { SEM }^{\mathrm{a}}\end{array}$ & $\begin{array}{l}\text { Cytotoxicity } \\
\mathrm{IC}_{50} \pm \mathrm{SEM}^{\mathrm{a}}\end{array}$ \\
\hline \multicolumn{5}{|c|}{ Category $A\left(R_{1}=F\right)$} \\
\hline 1 & & $\mathrm{NA}^{\mathrm{b}}$ & $\mathrm{NA}^{\mathrm{b}}$ & $\mathrm{NT}^{\mathrm{c}}$ \\
\hline 2 & & $\mathrm{NA}^{\mathrm{b}}$ & $378.03 \pm 0.75$ & $>30$ \\
\hline 3 & & $\mathrm{NA}^{\mathrm{b}}$ & $\mathrm{NA}^{\mathrm{b}}$ & $\mathrm{NT}^{\mathrm{c}}$ \\
\hline 4 & & $87.0 \pm 0.88$ & $\mathrm{NA}^{\mathrm{b}}$ & $\mathrm{NT}^{\mathrm{c}}$ \\
\hline 5 & & $\mathrm{NA}^{\mathrm{b}}$ & $\mathrm{NA}^{\mathrm{b}}$ & $\mathrm{NT}^{\mathrm{c}}$ \\
\hline 6 & & $\mathrm{NA}^{\mathrm{b}}$ & $\mathrm{NA}^{\mathrm{b}}$ & $\mathrm{NT}^{\mathrm{c}}$ \\
\hline 7 & & $\mathrm{NA}^{\mathrm{b}}$ & $\mathrm{NA}^{\mathrm{b}}$ & $\mathrm{NT}^{\mathrm{c}}$ \\
\hline 8 & & $30.3 \pm 1.01$ & $\mathrm{NA}^{\mathrm{b}}$ & $\mathrm{NT}^{\mathrm{c}}$ \\
\hline 9 & & $79.8 \pm 1.01$ & $\mathrm{NA}^{\mathrm{b}}$ & $\mathrm{NT}^{\mathrm{c}}$ \\
\hline 10 & & $193.7 \pm 0.66$ & $\mathrm{NA}^{\mathrm{b}}$ & $\mathrm{NT}^{\mathrm{c}}$ \\
\hline 11 & & $\mathrm{NA}^{\mathrm{b}}$ & $399.47 \pm 1.88$ & $>30$ \\
\hline 12 & & $\mathrm{NA}^{\mathrm{b}}$ & $465.33 \pm 1.99$ & $>30$ \\
\hline 13 & & $\mathrm{NA}^{\mathrm{b}}$ & $443.64 \pm 0.57$ & $>30$ \\
\hline 14 & & $187.3 \pm 1.75$ & $\mathrm{NA}^{\mathrm{b}}$ & $\mathrm{NT}^{\mathrm{c}}$ \\
\hline
\end{tabular}


Table 1 (continued)

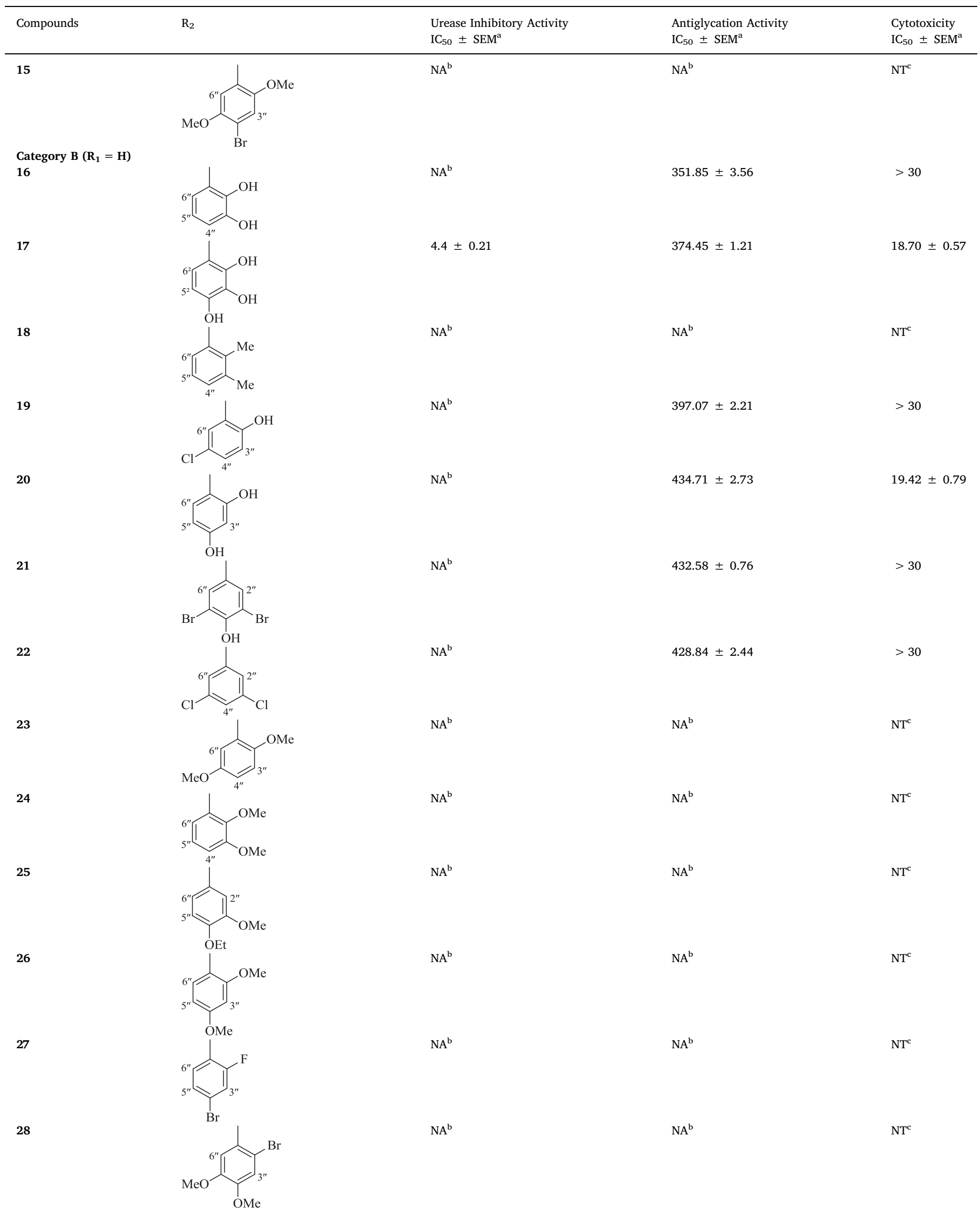


Table 1 (continued)

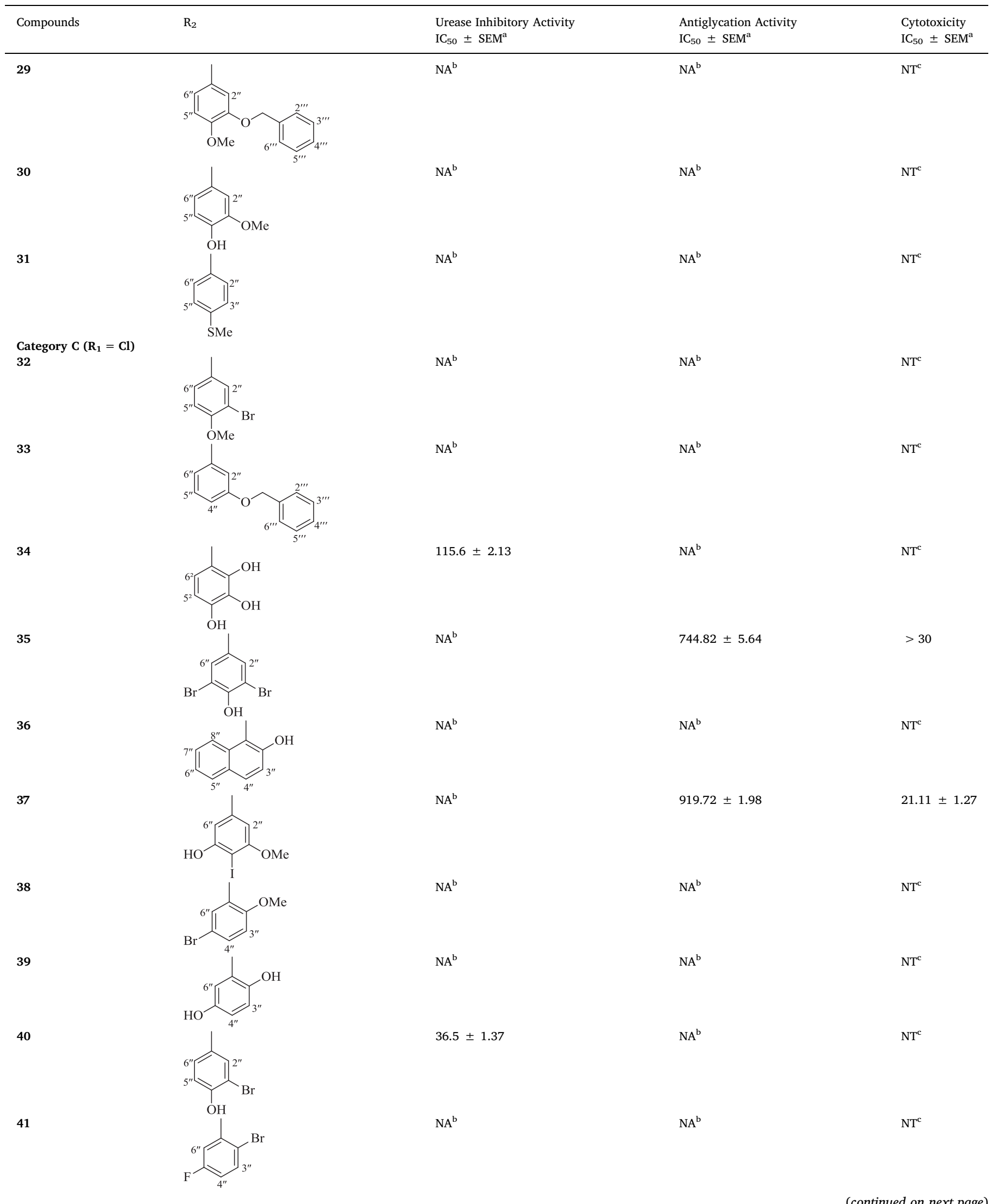


Table 1 (continued)

\begin{tabular}{lll}
\hline Compounds & $\begin{array}{l}\text { Urease Inhibitory Activity } \\
\mathrm{IC}_{50} \pm \mathrm{SEM}^{\mathrm{a}}\end{array}$ & $\begin{array}{l}\text { Antiglycation Activity } \\
\mathrm{IC}_{50} \pm \mathrm{SEM}^{\mathrm{a}}\end{array}$ \\
\hline 42 & & $333.63 \pm 1.98$ \\
$\mathrm{IC}_{50} \pm \mathrm{SEM}^{\mathrm{a}}$
\end{tabular}

$\mathrm{SEM}^{\mathrm{a}}$ (Standard error of mean); $\mathrm{NA}^{\mathrm{b}}$ (Not Active); $\mathrm{NT}^{\mathrm{c}}$ (Non Toxic); Thiourea ${ }^{\mathrm{d}}$ (Standard inhibitor of urease inhibitory activity); Rutin ${ }^{\mathrm{e}}$ (Standard inhibitor of antiglycation activity); Cycloheximide ${ }^{\mathrm{f}}$ (Standard inhibitor for cytotoxicity).

three compounds were found to be non-cytotoxic.

In category "C", compound $40\left(\mathrm{IC}_{50}=36.5 \pm 1.37 \mu \mathrm{M}\right)$ having 3 "bromo-4"-hydroxy substitutions, showed a urease inhibitory activity comparable to standard thiourea $\left(\mathrm{IC}_{50}=21.3 \pm 1.3 \mu \mathrm{M}\right)$ and found non-cytotoxic. The hydroxy group is apparently making the hydrogen bonding interaction as well as the bromo group involved in some polar interaction with the active site of the enzyme. Activity of compound $\mathbf{4 0}$ can be compared with analogs 44 and 35 which have additional methoxy and bromo group, respectively, at $5^{\prime \prime}$-position of $R_{2}$, a complete loss of activity was observed. The inactivity of the compounds might be due to the additional groups which create the steric hindrance for the hydroxy group to bind with the enzyme active site. However, compound 35 IC $\left._{50}=744.82 \pm 5.64 \mu \mathrm{M}\right)$ showed selective antiglycation activity and also found to be non-cytotoxic. Furthermore, non-cytotoxic compounds $42 \quad\left(\mathrm{IC}_{50}=333.63 \pm 1.98 \mu \mathrm{M}\right)$ and 37 $\left(\mathrm{IC}_{50}=919.72 \pm 1.98 \mu \mathrm{M}\right)$ showed a selective good to moderate antiglycation activity. Compound 42 has a $3^{\prime \prime}, 5^{\prime \prime}$-dibromo-4"-hydroxy substitution while compound 37 is with 4 "-bromo- 3 ", 5 "'-dimethoxy substitutions at phenyl ring $R_{2}$. It is worthy to note that compounds $\mathbf{3 5}$, 37 , and 42 , are $3^{\prime \prime}, 4^{\prime \prime}, 5^{\prime \prime}$-trisubstituted analogs which demonstrated the selective antiglycation potential. Another compound 34 $\left(\mathrm{IC}_{50}=115.6 \pm 2.13 \mu \mathrm{M}\right)$ having a $3^{\prime \prime}, 4^{\prime \prime}, 5^{\prime \prime}$-trihydroxy group, showed selective but weak urease inhibitory activity. Its activity compared with the structurally similar and most potent compound $\mathbf{1 7}$ $\left(\mathrm{IC}_{50}=4.4 \pm 0.21 \mu \mathrm{M}\right)$. Compound 34 might have a conformation which does not fit well into the active site of enzyme. Similarly, additional chloro groups at C- 6 and C-6' positions are not playing their role in the activity (Fig. 9).

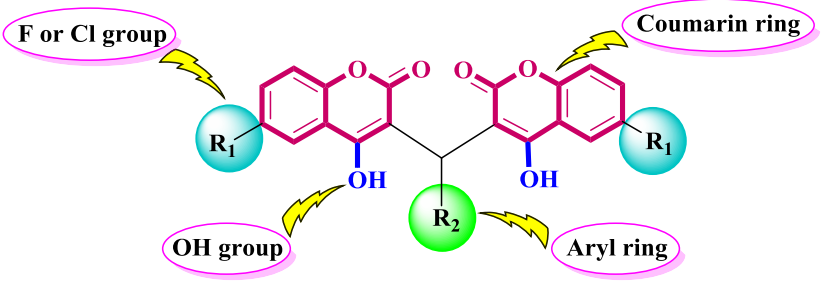

Fig. 3. General structural features of bis-coumarin.

In brief, it was observed that all derivatives, except 17 , were found to be selective and non-cytotoxic. Our next goal is to place heterocycles on bis-coumarin skeleton in order to see their effects on selectivity and cytotoxicity.

\section{Conclusion}

Synthetic bis-coumarins 1-44 were evaluated for their urease inhibitory and antiglycation activities. Seven derivatives 4, 8-10, 14, 34, and 40 showed selective urease inhibition, whereas, twelve analogs 2 , 11-13, 16, 17, 19-22, 35, 37, and 42 demonstrated antiglycation potential. Only compound 17 showed dual inhibition. All compounds were largely found to be non-cytotoxic. Newly identified compounds, based on bis-coumarin scaffold, may serve as leads for future research for more powerful, non-cytotoxic, and selective agents against urease and protein glycation.
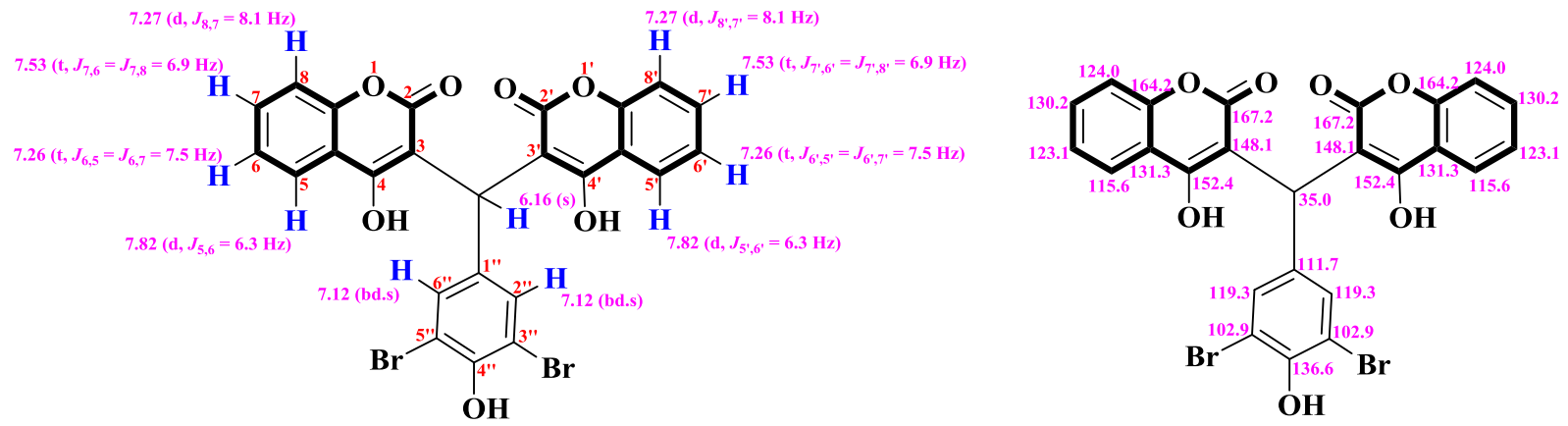

Fig. 2. ${ }^{1} \mathrm{H}$ - and ${ }^{13} \mathrm{C}$ NMR chemical shifts of compound 21. 


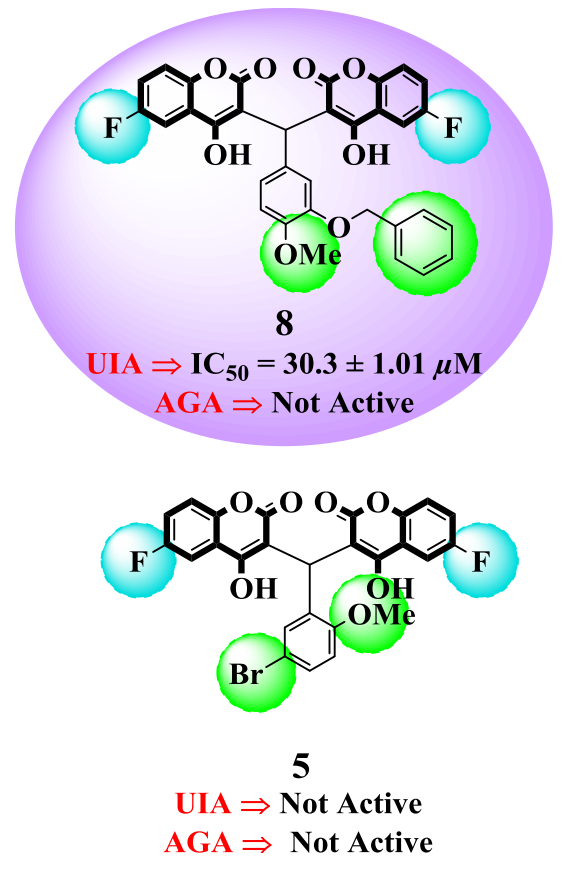

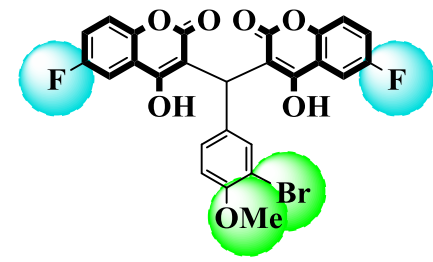

14

$\mathrm{UIA} \Rightarrow \mathrm{IC}_{50}=187.3 \pm 1.75 \mu \mathrm{M}$

AGA $\Rightarrow$ Not Active

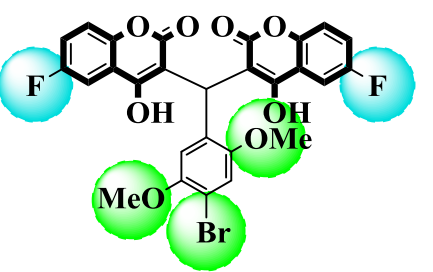

15

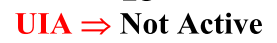

AGA $\Rightarrow$ Not Active

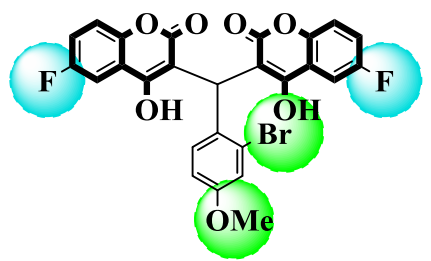

3

UIA $\Rightarrow$ Not Active

AGA $\Rightarrow$ Not Active

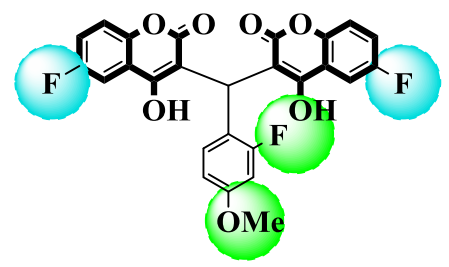

2

$\mathrm{UIA} \Rightarrow$ Not Active

$\mathrm{AGA} \Rightarrow \mathrm{IC}_{\mathbf{5 0}}=378.03 \pm 0.75 \mu \mathrm{M}$

Fig. 4. Structure-activity relationship of compounds 2, 3, 5, 8, 14, and 15.

\section{Experimental}

\subsection{Materials and methods}

Thin layer chromatography (TLC) was performed on pre-coated silica gel aluminum plates (Kieselgel 60 F-254, $0.20 \mathrm{~mm}$, Merck, Darmstadt, Germany). Chromatograms were visualized by using a handhold UV lamp at 254, and $365 \mathrm{~nm}$ or placing in iodine vapors. Fast atom bombardement mass spectra (FAB MS) were recorded on a Finnigan MAT-311A (Germany) (70 eV) spectrometers, electrospray ionization mass spectra (ESI-MS, HRESI-MS) were recorded on a QSTAR XL LCMS-MS, and ABSciex (Germany) ( $50 \mathrm{kV})$ mass spectrometers, and the data are tabulated as $m / z .{ }^{1} \mathrm{H}$ - and ${ }^{13} \mathrm{C}$ NMR spectroscopic analysis was performed on an Avance Bruker (Germany) AM spectrometer $300 \mathrm{MHz}$ machine. Splitting patterns for ${ }^{1} \mathrm{H}$ NMR spectra were as follows, s (singlet); d (doublet); $\mathrm{t}$ (triplet); $\mathrm{m}$ (multiplet). Chemical shifts are reported in $\delta(\mathrm{ppm})$ and coupling constants are given in Hz. All solvents and reagents were of reagent grade, and used directly without purification. Melting points of the compounds were determined on Büchi-M560 melting point apparatus.

\subsection{General procedure for the syntheses of bis-coumarin derivatives 1-44}

6-Fluoro-4-hydroxy /6-chloro-4-hydroxy /4-hydroxy coumarin ( $1 \mathrm{mmol})$, and a variety of aromatic aldehydes $(0.5 \mathrm{mmol})$, as well as
$10 \mathrm{~mol} \%$ of tetraethylammonium bromide (TEAB) were dissolved in distilled water $(15 \mathrm{~mL})$ in a $100 \mathrm{~mL}$ round-bottommed flask. The reaction mixture was refluxed for $2 \mathrm{~h}$. Periodic TLC was taken to check the progress of reaction. Resulting precipitates were filtered, and washed with distilled water. This afforded products 1-44 in high yields.

\subsection{3,3'-((2",3"-Dimethoxyphenyl)methylene)bis(6-fluoro-4-hydroxy- 2H-chromen-2-one) (1)}

White Solid; Yield: $82 \%$; M.p.: $>300{ }^{\circ} \mathrm{C} \mathrm{dec} . ;{ }^{1} \mathrm{H}$ NMR $(300 \mathrm{MHz}$, Acetone- $d_{6}$ ): $\delta 11.25$ (s, $\left.2 \mathrm{H}, 2 \mathrm{OH}\right), 7.67\left(\mathrm{~d}, J_{5,6 / 5^{\prime}, 6^{\prime}}=8.7 \mathrm{~Hz}, 2 \mathrm{H}, \mathrm{H}-5\right.$, H-5'), 7.50 (d, $J_{7,8 / 7^{\prime}, 8^{\prime} / 8,7 / 8^{\prime}, 7^{\prime}}=5.4 \mathrm{~Hz}, 4 \mathrm{H}, \mathrm{H}-7, \mathrm{H}-8, \mathrm{H}-7^{\prime}, \mathrm{H}-8^{\prime}$ ), 7.01 (m, 3H, H-4", H-5", H-6"), 6.22 (s, $1 \mathrm{H},-\mathrm{CH}-$ ), 3.81 (s, 3H, $\mathrm{OCH}_{3 \mathrm{a}}$ ), 3.49 (s, 3H, $\left.\mathrm{OCH}_{3 \mathrm{~b}}\right) ;{ }^{13} \mathrm{C}$ NMR $\left(75 \mathrm{MHz}\right.$, DMSO- $\left.d_{6}\right): \delta 165.8,165.8$, $163.8,168.3,159.3,159.3,156.1,152.3,148.5,146.4,136.0,124.4$, $122.3,121.1,121.0,120.9,118.1,117.8,117.5,117.3,110.5,109.3$, 108.9, 104.5, 59.3, 55.4, 32.7; FAB (Pos.)-MS $m / z=509\left[\mathrm{M}+\mathrm{H}^{+}\right.$; ESI-MS $m / z=509[\mathrm{M}+\mathrm{H}]^{+}$; HRESI-MS Calcd for $\mathrm{C}_{27} \mathrm{H}_{19} \mathrm{~F}_{2} \mathrm{O}_{8}[\mathrm{M}$ $+\mathrm{H}]^{+}: m / z=509.1047$, found 509.1090.

4.4. 3,3'-((2"-Fluoro-4"'-methoxyphenyl)methylene)bis(6-fluoro-4hydroxy-2H-chromen-2-one) (2)

White Solid; Yield: 87\%; M.p.: $>300{ }^{\circ} \mathrm{C}$ dec.; ${ }^{1} \mathrm{H}$ NMR $(300 \mathrm{MHz}$, DMSO- $d_{6}$ ): $\delta 11.31$ (bd.s, $2 \mathrm{H}, 2 \mathrm{OH}$ ), 7.68 (d, $J_{5,6 \mathrm{~F} / 5^{\prime}, 6 \mathrm{~F}}=8.7 \mathrm{~Hz}, 2 \mathrm{H}, \mathrm{H}-$
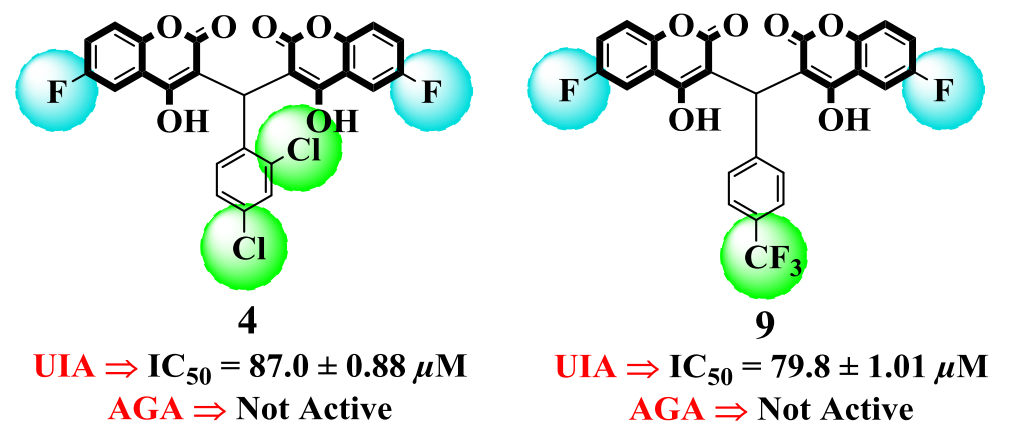

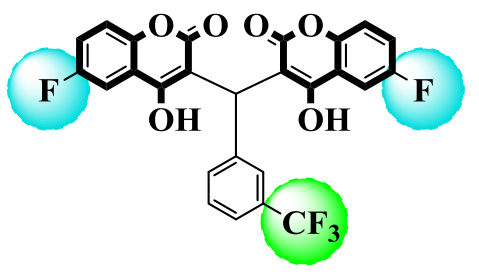

10

$$
\begin{gathered}
\text { UIA } \Rightarrow \text { IC }_{50}=193.7 \pm 0.66 \mu \mathrm{M} \\
\text { AGA } \Rightarrow \text { Not Active }
\end{gathered}
$$

Fig. 5. Structure-activity relationship of compounds 4, 9, and 10 . 


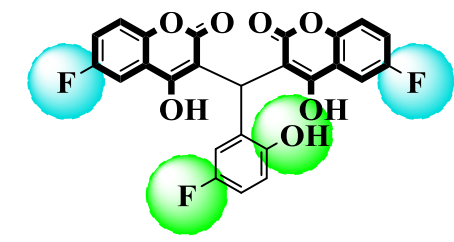

11

UIA $\Rightarrow$ Not Active
$\mathrm{AGA} \Rightarrow \mathrm{IC}_{50}=\mathbf{3 9 9 . 4 7} \pm 1.88 \mu \mathrm{M}$

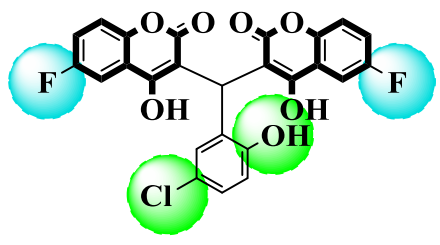

12

UIA $\Rightarrow$ Not Active

$\mathrm{AGA} \Rightarrow \mathrm{IC}_{50}=465.33 \pm 1.99 \mu \mathrm{M}$

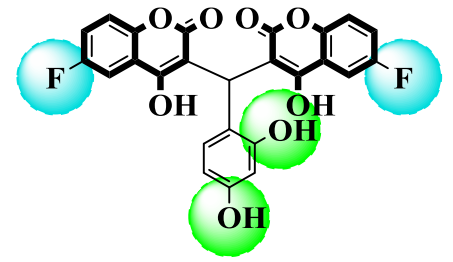

13

Fig. 6. Structure-activity relationship of compounds 11-13.

5, H-5'), 7.52 (d, $\left.J_{8,7 / 8^{\prime}, 7^{\prime} / 6^{\prime \prime}, 5^{\prime \prime}}=5.4 \mathrm{~Hz}, 3 \mathrm{H}, \mathrm{H}-8, \mathrm{H}-8^{\prime}, \mathrm{H}-6^{\prime \prime}\right), 7.32$ (m, 1H, H-3"), 6.75 (m, 3H, H-7, H-7', H-5"), 6.19 (bd.s, 1H, -CH-), 3.80 (s, $\left.3 \mathrm{H}, \mathrm{OCH}_{3}\right) ;{ }^{13} \mathrm{C}$ NMR $\left(75 \mathrm{MHz}, \mathrm{DMSO}-d_{6}\right): \delta 160.2,159.9,159.9$, $159.2,159.2$, 156.7, 149.7, 148.5, 129.1, 120.0, 119.7, 119.3, 118.7, 118.4, 117.4, 117.3, 114.9, 114.8, 113.6, 112.1, 109.5, 109.2, 108.5, 101.5, 55.5, 28.3; FAB (Neg.)-MS $m / z=495\left[^{[M-H}\right]^{-1}$; ESI-MS $m /$ $z=477[\mathrm{M}+\mathrm{H}-\mathrm{HF}]^{+}$; HRESI-MS Calcd for $\mathrm{C}_{26} \mathrm{H}_{15} \mathrm{~F}_{2} \mathrm{O}_{7}[\mathrm{M}+\mathrm{H}-\mathrm{HF}]^{+}$: $m / z=477.0785$, Found 477.0787.

4.5. 3,3'-((2"-Bromo-4"-methoxyphenyl)methylene)bis(6-fluoro-4hydroxy-2H-chromen-2-one) (3)

White Solid; Yield: 79\%; M.p.: $230-232{ }^{\circ} \mathrm{C}$; ${ }^{1} \mathrm{H}$ NMR $(300 \mathrm{MHz}$, Acetone- $d_{6}$ ): $\delta 11.47$ (bd.s, $\left.2 \mathrm{H}, 2 \mathrm{OH}\right), 7.68\left(\mathrm{~d}, J_{5,6 \mathrm{~F} / 5^{\prime}, 6 \mathrm{~F}}=8.1 \mathrm{~Hz}, 2 \mathrm{H}\right.$, H-5, H-5'), 7.52 (bd.s, 5H, H-7, H-8, H-7', H-8', H-3'), 7.32 (d, $\left.J_{6^{\prime \prime}, 5^{\prime \prime}}=8.1 \mathrm{~Hz}, 1 \mathrm{H}, \mathrm{H}-6^{\prime \prime}\right), 7.02\left(\mathrm{~d}, J_{5^{\prime \prime}, 6^{\prime \prime}}=8.1 \mathrm{~Hz}, 1 \mathrm{H}, \mathrm{H}-5^{\prime \prime}\right), 6.15$ (bd.s, $1 \mathrm{H},-\mathrm{CH}-$ ), 3.86 (bd.s, $3 \mathrm{H}, \mathrm{OCH}_{3}$ ); ${ }^{13} \mathrm{C}$ NMR $(75 \mathrm{MHz}$, DMSO$\left.d_{6}\right): \delta 160.1,160.1,159.5,159.5,156.9,149.9,148.8,129.2,125.2$, 120.0, 119.8, 119.4, 118.9, 118.6, 117.6, 117.4, 114.8, 114.6, 113.7, $112.3,109.4,109.2,108.4,101.6,55.7,28.5$; FAB (Neg.)-MS m/ $z=556[\mathrm{M}-\mathrm{H}]^{-1}, 558[\mathrm{M}+2-\mathrm{H}]^{-1}$; ESI-MS $m / z=557[\mathrm{M}+\mathrm{H}]^{+}, 559$ $[\mathrm{M}+2+\mathrm{H}]^{+}$; HRESI-MS Calcd for $\mathrm{C}_{26} \mathrm{H}_{15} \mathrm{BrF}_{2} \mathrm{O}_{7}[\mathrm{M}+\mathrm{H}]^{+}: \mathrm{m} /$ $z=557.0047$, Found 557.0010.

4.6. 3,3'-((2", 4"-Dichlorophenyl)methylene)bis(6-fluoro-4-hydroxy-2Hchromen-2-one) (4)

White Solid; Yield: 81\%; M.p.: > $300{ }^{\circ} \mathrm{C}$ dec.; ${ }^{1} \mathrm{H}$ NMR $(300 \mathrm{MHz}$, Acetone- $d_{6}$ ): $\delta 7.68\left(\mathrm{dd}, J_{5,7 / / 5^{\prime}, 7^{\prime}}=2.1 \mathrm{~Hz}, J_{5,6 \mathrm{~F} / 5^{\prime}, 6 \mathrm{~F}^{\prime}}=7.8 \mathrm{~Hz}, 2 \mathrm{H}, \mathrm{H}-\right.$ 5, H-5') 7.57 (d, $J_{6^{\prime \prime}, 5^{\prime \prime}}=8.4 \mathrm{~Hz}, 1 \mathrm{H}, \mathrm{H}-6^{\prime \prime}$ ), 7.49 (m, 4H, H-8, H-8', H$3^{\prime \prime}, \mathrm{H}-5^{\prime \prime}$ ), 7.39 (dd, $J_{7,5 / 7^{\prime}, 5^{\prime}}=2.1 \mathrm{~Hz}, J_{7,8 / 7^{\prime}, 8^{\prime}}=6.6 \mathrm{~Hz}, 2 \mathrm{H}, \mathrm{H}-7, \mathrm{H}-7^{\prime}$ ), 6.24 (s, $1 \mathrm{H},-\mathrm{CH}-$ ); ${ }^{13} \mathrm{C}$ NMR (75 MHz, DMSO- $d_{6}$ ): $\delta$ 160.4, 160.1, 159.3, 157.1, 156.5, 156.1, 148.2, 148.0, 141.5, 135.4, 132.5, 131.7, $130.0,126.6,125.0,124.9,119.1,119.0,115.2,115.0,111.4,111.3$, 100.2, 100.0, 28.2; FAB (Neg.)-MS $m / z=516[\mathrm{M}-\mathrm{H}]^{-1}, 518[\mathrm{M}+2-$ $\mathrm{H}]^{-1}$; ESI-MS $m / z=517[\mathrm{M}+\mathrm{H}]^{+}$; HRESI-MS Calcd for $\mathrm{C}_{25} \mathrm{H}_{13} \mathrm{Cl}_{2} \mathrm{~F}_{2} \mathrm{O}_{6}$ $[\mathrm{M}+\mathrm{H}]^{+}: m / z=517.0057$, Found 517.0071.
4.7. 3,3'-((5"'-Bromo-2"'-methoxyphenyl)methylene)bis(6-fluoro-4hydroxy-2H-chromen-2-one) (5)

White Solid; Yield: $77 \%$; M.p.: $245-247^{\circ} \mathrm{C}$; ${ }^{1} \mathrm{H}$ NMR $(300 \mathrm{MHz}$, Acetone- $d_{6}$ ): $\delta 11.21$ (bd.s, $2 \mathrm{H}, 2 \mathrm{OH}$ ), 7.67 (d, $J_{5,6 \mathrm{~F} / 5^{\prime}, 6 \mathrm{~F}^{\prime}}=8.7 \mathrm{~Hz}, 2 \mathrm{H}$, H-5, H-5'), 7.51 (d, $J_{8,7 / 8^{\prime}, 7^{\prime} / 6^{\prime \prime}, 4^{\prime \prime}}=5.7 \mathrm{~Hz}, 3 \mathrm{H}, \mathrm{H}-8, \mathrm{H}-8^{\prime}, \mathrm{H}-6^{\prime \prime}$ ), 7.43 (bd.s, $2 \mathrm{H}, \mathrm{H}-7, \mathrm{H}-7^{\prime}$ ), 6.96 (d, $J_{3^{\prime \prime}, 4^{\prime \prime} / 4^{\prime \prime}, 3^{\prime \prime}}=8.7 \mathrm{~Hz}, 2 \mathrm{H}, \mathrm{H}-3^{\prime \prime}, \mathrm{H}-4^{\prime \prime}$ ), 6.14 (s, $1 \mathrm{H},-\mathrm{CH}-$ ), $3.61\left(\mathrm{~s}, 3 \mathrm{H}, \mathrm{OCH}_{3 \mathrm{a}}\right) ;{ }^{13} \mathrm{C}$ NMR (75 MHz, DMSO- $\left.\mathrm{d}_{6}\right): \delta$ $165.8,165.8,163.5,159.3,157.5,156.5,156.2$, 148.5, 148.5, 133.1, $131.1,129.2,124.2,120.8,120.7,118.3,117.9,117.6,117.4,113.2$, $111.4,109.3,109.0,103.7,55.8,32.9 ;$ FAB (Neg.)-MS $m / z=556[\mathrm{M}-$ $\mathrm{H}]_{,}^{-1} 558[\mathrm{M}+2-\mathrm{H}]^{-1}$; ESI-MS $m / z=557[\mathrm{M}+\mathrm{H}]^{+}, 559[\mathrm{M}+2+\mathrm{H}]^{+}$; HRESI-MS Calcd for $\mathrm{C}_{26} \mathrm{H}_{16} \mathrm{BrF}_{2} \mathrm{O}_{7}[\mathrm{M}+\mathrm{H}]^{+}: m / z=557.0047$, Found 557.0010 .

4.8. 3,3'-(p-Tolylmethylene)bis(6-fluoro-4-hydroxy-2H-chromen-2-one) (6)

White Solid; Yield: 76\%; M.p.: $>300{ }^{\circ} \mathrm{C}$ dec.; ${ }^{1} \mathrm{H}$ NMR $(300 \mathrm{MHz}$, Acetone- $\left.d_{6}\right): \delta 11.43(\mathrm{~s}, 2 \mathrm{H}, 2 \mathrm{OH}), 7.68\left(\mathrm{~d}, J_{5,6 \mathrm{~F} / 5^{\prime}, 6 \mathrm{~F}}=8.7 \mathrm{~Hz}, 2 \mathrm{H}, \mathrm{H}-5\right.$, H-5'), 7.54 (d, $J_{8,7 / 8^{\prime}, 7^{\prime} / 7,8}=5.7 \mathrm{~Hz}, 3 \mathrm{H}, \mathrm{H}-7, \mathrm{H}-8, \mathrm{H}-8^{\prime}$ ), 7.21 (d, $J_{2^{\prime \prime}, 3^{\prime \prime}}$, $\left.6^{\prime \prime}, 5^{\prime \prime} / 7^{\prime}, 8^{\prime}=8.1 \mathrm{~Hz}, 3 \mathrm{H}, \mathrm{H}-7^{\prime}, \mathrm{H}-2^{\prime \prime}, \mathrm{H}-6^{\prime \prime}\right), 7.14\left(\mathrm{~d}, J_{3^{\prime \prime}, 2^{\prime \prime} / 5^{\prime \prime}, 6^{\prime \prime}}=8.1 \mathrm{~Hz}\right.$, $2 \mathrm{H}, \mathrm{H}-3^{\prime \prime}, \mathrm{H}-5^{\prime \prime}$ ), 6.10 (bd.s, $1 \mathrm{H},-\mathrm{CH}-$ ), 2.29 (s, 3H, $\mathrm{CH}_{3}$ ); FAB (Neg.)MS $m / z=461[\mathrm{M}-\mathrm{H}]^{-1}$; ESI-MS $m / z=463[\mathrm{M}+\mathrm{H}]^{+}$; HRESI-MS Calcd for $\mathrm{C}_{26} \mathrm{H}_{17} \mathrm{~F}_{2} \mathrm{O}_{6}[\mathrm{M}+\mathrm{H}]^{+}: m / z=463.0993$, Found 463.1022 .

\subsection{3,3'-((2",5'-Dimethoxyphenyl)methylene)bis(6-fluoro-4-hydroxy- 2H-chromen-2-one) (7)}

White Solid; Yield: $72 \%$; M.p.: $240-242{ }^{\circ} \mathrm{C} ;{ }^{1} \mathrm{H}$ NMR $(300 \mathrm{MHz}$, Acetone- $\left.d_{6}\right): \delta 11.20(\mathrm{~s}, 2 \mathrm{H}, 2 \mathrm{OH}), 7.67\left(\mathrm{~d}, J_{5,6 \mathrm{~F} / 5^{\prime}, 6 \mathrm{~F}}=8.7 \mathrm{~Hz}, 2 \mathrm{H}, \mathrm{H}-5\right.$, H-5'), 7.50 (d, $J_{7,8 / 7^{\prime}, 8^{\prime} / 8,7 / 8^{\prime}, 7^{\prime}}=5.7 \mathrm{~Hz}, 4 \mathrm{H}, \mathrm{H}-7, \mathrm{H}-8, \mathrm{H}-7^{\prime}, \mathrm{H}-8^{\prime}$ ), 6.91 (m, 3H, H-3", H-4", H-6"), 6.10 (s, $1 \mathrm{H},-\mathrm{CH}-$ ), 3.68 (s, 3H, $\mathrm{OCH}_{3 \mathrm{a}}$ ), $3.52\left(\mathrm{~s}, 3 \mathrm{H}, \mathrm{CH}_{3 \mathrm{~b}}\right) ;{ }^{13} \mathrm{C}$ NMR $\left(75 \mathrm{MHz}\right.$, DMSO- $\left.\mathrm{d}_{6}\right): \delta 165.1,165.1$, 163.7, 163.7, 159.3, 159.3, 156.2, 152.6, 148.5, 146.3, 131.4, 125.3, $120.5,120.4,118.3,118.0,117.6,117.5,116.4,111.9,109.6,109.3$, $108.9,104.4,56.2,55.0,33.0$; FAB (Neg.)-MS $m / z=507[\mathrm{M}-\mathrm{H}]^{-1}$; ESI-MS $m / z=509[\mathrm{M}+\mathrm{H}]^{+}$; HRESI-MS Calcd for $\mathrm{C}_{27} \mathrm{H}_{19} \mathrm{~F}_{2} \mathrm{O}_{8}$ [M $+\mathrm{H}]^{+}: m / z=509.1047$, Found 509.1064.

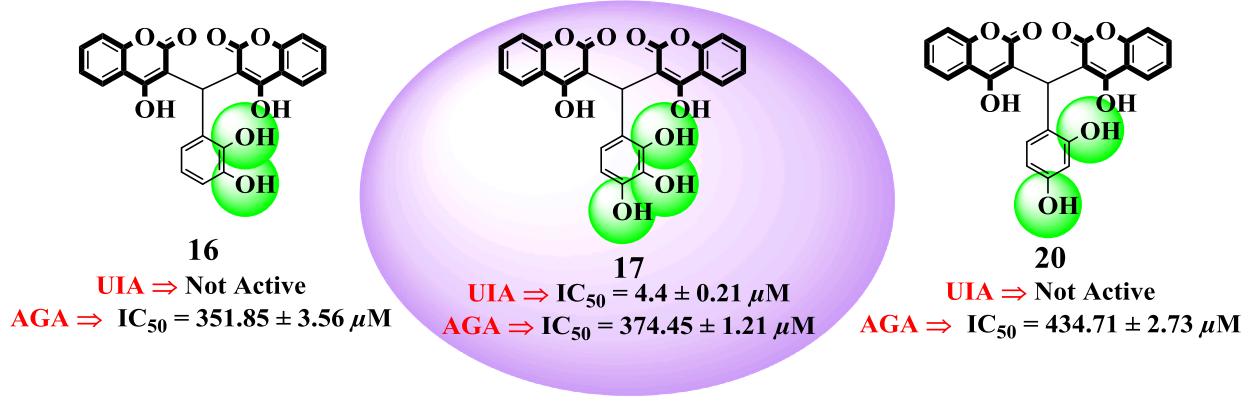

Fig. 7. Structure-activity relationship of compounds 16, 17, and 20. 


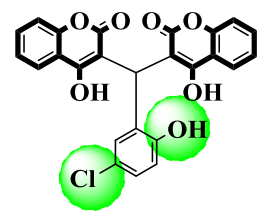

19

UIA $\Rightarrow$ Not Active

$\mathrm{AGA} \Rightarrow \mathrm{IC}_{50}=397.07 \pm 2.21 \mu \mathrm{M}$

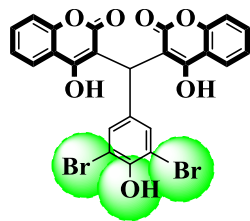

21

UIA $\Rightarrow$ Not Active

$\mathrm{AGA} \Rightarrow \mathrm{IC}_{50}=432.58 \pm 0.76 \mu \mathrm{M}$

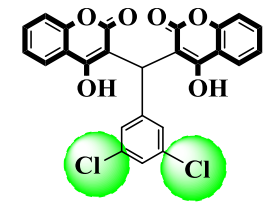

22

UIA $\Rightarrow$ Not Active

$\mathrm{AGA} \Rightarrow \mathrm{IC}_{\mathbf{5 0}}=\mathbf{4 2 8 . 8 4} \pm \mathbf{2 . 4 4} \mu \mathrm{M}$

Fig. 8. Structure-activity relationship of compounds 19, 21, and 22.

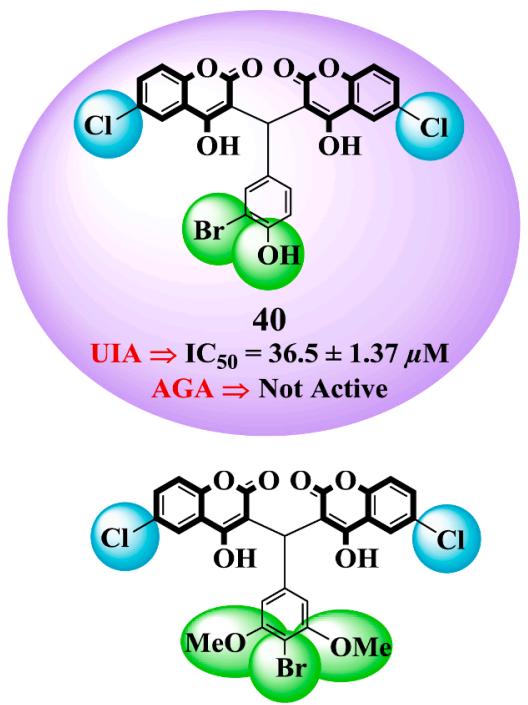

42

UIA $\Rightarrow$ Not Active

$\mathrm{AGA} \Rightarrow \mathrm{IC}_{\mathbf{5 0}}=333.63 \pm 1.98 \mu \mathrm{M}$

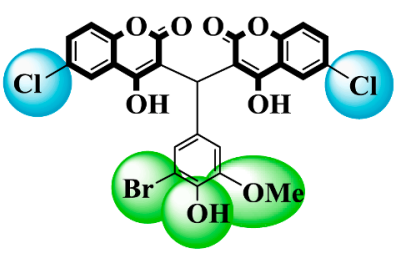

44

UIA $\Rightarrow$ Not Active

AGA $\Rightarrow$ Not Active

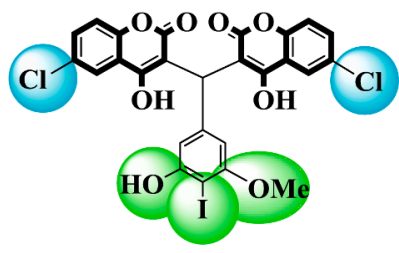

37

UIA $\Rightarrow$ Not Active

$\mathrm{AGA} \Rightarrow \mathrm{IC}_{\mathbf{5 0}}=919.72 \pm 1.98 \mu \mathrm{M}$

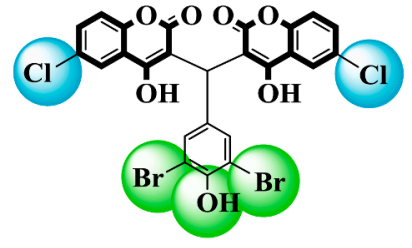

35

UIA $\Rightarrow$ Not Active

$\mathrm{AGA} \Rightarrow \mathrm{IC}_{\mathbf{5 0}}=\mathbf{7 4 4 . 8 2} \pm \mathbf{5 . 6 4} \boldsymbol{\mu \mathrm { M }}$

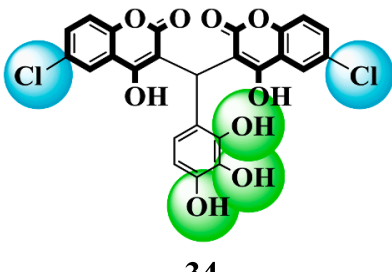

34

$\mathrm{UIA} \Rightarrow \mathrm{IC}_{50}=115.6 \pm 2.13 \mu \mathrm{M}$

AGA $\Rightarrow$ Not Active

Fig. 9. Structure-activity relationship of compounds $34,35,37,40,42$, and 44.

4.10. 3,3'-((3'-(Benzyloxy)-4"'-methoxyphenyl)methylene)bis(6-fluoro-4hydroxy-2H-chromen-2-one) (8)

White Solid; Yield: 80\%; M.p.: $200-202{ }^{\circ} \mathrm{C}$; ${ }^{1} \mathrm{H}$ NMR $(300 \mathrm{MHz}$, Acetone- $d_{6}$ ): $\delta 11.41$ (s, 2H, 2OH), 7.66 (d, $J_{5,6 \mathrm{~F} / 5^{\prime}, 6 \mathrm{~F}}=8.4 \mathrm{~Hz}, 2 \mathrm{H}, \mathrm{H}-5$, H-5'), 7.54 (bd.d, $J_{8,7 / 8^{\prime}, 7^{\prime} / 7,8 / 7^{\prime}, 8^{\prime}}=5.4 \mathrm{~Hz}, 4 \mathrm{H}, \mathrm{H}-7, \mathrm{H}-8, \mathrm{H}-7^{\prime}, \mathrm{H}-8^{\prime}$ ), 7.27 (m, 5H, Ar-H), 6.96 (bd.s, $\left.1 \mathrm{H}, \mathrm{H}-2^{\prime \prime}\right), 6.93$ (d, $J_{5^{\prime \prime}, 6^{\prime \prime}}=7.5 \mathrm{~Hz}, 1 \mathrm{H}$, $\left.\mathrm{H}-5^{\prime \prime}\right), 6.87$ (d, $\left.J_{6^{\prime \prime}, 5^{\prime \prime}}=8.0 \mathrm{~Hz}, 1 \mathrm{H}, \mathrm{H}-6^{\prime \prime}\right), 6.05$ (s, $1 \mathrm{H},-\mathrm{CH}-$ ), 4.97 (s, $\left.2 \mathrm{H},-\mathrm{CH}_{2}-\right), 3.80\left(\mathrm{~s}, 3 \mathrm{H}, \mathrm{OCH}_{3}\right) ;{ }^{13} \mathrm{C}$ NMR $\left(100 \mathrm{MHz}, \mathrm{DMSO}-d_{6}\right): \delta$ 162.7, 162.7, 161.6, 161.6, 159.4, 159.4, 149.5, 148.2, 148.2, 146.9, 136.6, 135.4, 128.7, 128.7, 127.5, 127.2, 127.2, 125.3, 125.3, 122.0, $119.2,119.2,115.0,115.0,114.2,112.4,111.5,111.5,100.3,100.3$, 71.4, 56.2, 28.4; FAB (Neg.)-MS $m / z=582[\mathrm{M}-\mathrm{H}]^{-1}$; ESI-MS $m /$ $z=585[\mathrm{M}+\mathrm{H}]^{+}$; HRESI-MS Calcd for $\mathrm{C}_{33} \mathrm{H}_{23} \mathrm{~F}_{2} \mathrm{O}_{8}[\mathrm{M}+\mathrm{H}]^{+}: \mathrm{m} /$ $z=585.1360$, Found 585.1332.

4.11. 3,3'-((4"-(Trifluoromethyl)phenyl)methylene)bis(6-fluoro-4hydroxy-2H-chromen-2-one) (9)

White Solid; Yield: $84 \%$; M.p.: $>300{ }^{\circ} \mathrm{C} \mathrm{dec}$.; ${ }^{1} \mathrm{H}$ NMR $(300 \mathrm{MHz}$, DMSO- $d_{6}$ ): $\delta 7.53$ (d, $J_{5,6 \mathrm{~F} / 5^{\prime}, 6 \mathrm{~F}}=8.4 \mathrm{~Hz}, 2 \mathrm{H}, \mathrm{H}-5, \mathrm{H}-5^{\prime}$ ), 7.49 (dd, $\left.J_{3^{\prime \prime}, 5^{\prime \prime} / 5^{n}, 3^{\prime \prime}}=3.0 \mathrm{~Hz}, J_{3^{n}, 2^{\prime \prime} / 5^{n}, 6^{n}}=6.0 \mathrm{~Hz}, 2 \mathrm{H}, \mathrm{H}-3^{\prime \prime}, \mathrm{H}-5^{\prime \prime}\right), 7.37$ (m, 4H, H-8, H-8, H-2 ${ }^{\prime}, \mathrm{H}-6^{\prime \prime}$ ), 7.29 (d, $J_{7,8 / 7^{\prime}, 8^{\prime}}=8.4 \mathrm{~Hz}, 2 \mathrm{H}, \mathrm{H}-7, \mathrm{H}-7^{\prime}$ ), 6.29 (bd.s, $1 \mathrm{H},-\mathrm{CH}-)$; ${ }^{13} \mathrm{C}$ NMR (100 MHz, DMSO-d $\left.d_{6}\right): \delta 162.8,162.8$, 161.4, 161.4, 159.6, 159.6, 148.0, 148.0, 147.6, 128.9, 128.9, 128.4, $125.3,125.3,125.1,125.1,124.3,119.4,119.4,115.5,115.5,111.6$, 111.6, 100.9, 100.9, 28.4; FAB (Neg.)-MS $m / z=515$ [M-H] $^{-1}$; ESI-MS $m / z=517[\mathrm{M}+\mathrm{H}]^{+}$; HRESI-MS Calcd for $\mathrm{C}_{26} \mathrm{H}_{14} \mathrm{~F}_{5} \mathrm{O}_{6}[\mathrm{M}+\mathrm{H}]^{+}: m /$ $z=517.0710$, Found 517.0755.
4.12. 3,3'-((3"'-(Trifluoromethyl)phenyl)methylene)bis(6-fluoro-4hydroxy-2H-chromen-2-one) (10)

White Solid; Yield: 77\%; M.p.: $>300{ }^{\circ} \mathrm{C} \mathrm{dec} . ;{ }^{1} \mathrm{H}$ NMR $(300 \mathrm{MHz}$, Acetone- $d_{6}$ ): $\delta 11.52$ (bd.s, $2 \mathrm{H}, 2 \mathrm{OH}$ ), 7.69 (m, 4H, H-5, H-8, H-5', H$8^{\prime}$ ), 7.55 (m, 6H, H-7, H-7', H-2", H-4", H-5", H-6"), 6.30 (s, 1H, -CH-); ${ }^{13} \mathrm{C}$ NMR $\left(100 \mathrm{MHz}, \mathrm{DMSO}-\mathrm{d}_{6}\right): \delta 162.8,162.8,161.4,161.4,159.6$, 159.6, 148.0, 148.0, 142.7, 131.2, 130.7, 128.7, 127.3, 125.3, 125.3, $124.5,122.2$, 119.4, 119.4, 115.5, 115.5, 111.6, 111.6, 100.9, 100.9,

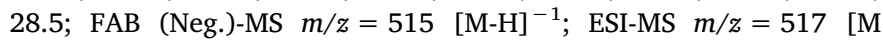
$+\mathrm{H}]^{+}$; HRESI-MS Calcd for $\mathrm{C}_{26} \mathrm{H}_{14} \mathrm{~F}_{5} \mathrm{O}_{6}[\mathrm{M}+\mathrm{H}]^{+}: \mathrm{m} / z=517.0710$, Found 517.0755.

4.13. 3,3'-((5'-Fluoro-2"-hydroxyphenyl)methylene)bis(6-fluoro-4hydroxy-2H-chromen-2-one) (11)

White Solid; Yield: 73\%; M.p.: $>300{ }^{\circ} \mathrm{C}$ dec.; ${ }^{1} \mathrm{H}$ NMR $(300 \mathrm{MHz}$, DMSO- $\left.d_{6}\right): \delta 7.88$ (m, $\left.1 \mathrm{H}, \mathrm{H}-5\right), 7.75\left(\mathrm{~m}, 1 \mathrm{H}, \mathrm{H}-5^{\prime}\right), 7.61(\mathrm{~m}, 2 \mathrm{H}, \mathrm{H}-8, \mathrm{H}-$ 8'), 7.46 (m, 3H, H-7, H-7', H-6"), 7.19 (m, 1H, H-4'), 6.98 (m, 1H, H$\left.3^{\prime \prime}\right), 5.69(\mathrm{~s}, 1 \mathrm{H},-\mathrm{CH}-) ;{ }^{13} \mathrm{C}$ NMR $\left(100 \mathrm{MHz}\right.$, DMSO-d $\left.d_{6}\right): \delta 162.2$, $161.9,160.5,160.1,159.5,159.0,155.2,151.6,149.5,148.8,125.6$, $125.1,122.5,119.9,119.5,117.6,117.2,117.0,114.8,114.7,109.7$, 109.4, 101.6, 101.4, 28.5; FAB (Neg.)-MS $m / z=462[\mathrm{M}-\mathrm{H}-\mathrm{HF}]^{-1}$; ESI-MS $m / z=465\left[\mathrm{M}+\mathrm{H}-\mathrm{H}_{2} \mathrm{O}\right]^{+}$; HRESI-MS Calcd for $\mathrm{C}_{25} \mathrm{H}_{12} \mathrm{~F}_{3} \mathrm{O}_{6}[\mathrm{M}$ $\left.+\mathrm{H}_{-} \mathrm{H}_{2} \mathrm{O}\right]^{+}: m / z=465.0585$, Found 465.0549 . 
4.14. 3,3'-((5'-Chloro-2'-hydroxyphenyl)methylene)bis(6-fluoro-4hydroxy-2H-chromen-2-one) (12)

White Solid; Yield: 79\%; M.p.: > $300{ }^{\circ} \mathrm{C} \mathrm{dec} . ;{ }^{1} \mathrm{H}$ NMR $(300 \mathrm{MHz}$, Acetone- $d_{6}$ ): $\delta 7.84$ (m, 2H, H-5, H-5'), 7.50 (m, 7H, H-7, H-8, H-7', H$8^{\prime}, \mathrm{H}-3^{\prime \prime}, \mathrm{H}-4^{\prime \prime}, \mathrm{H}-6^{\prime \prime}$ ), 5.79 (s, 1H, -CH-); ${ }^{13} \mathrm{C}$ NMR (100 MHz, DMSO$\left.d_{6}\right): \delta 162.5,162.2,160.4,160.0,159.6,159.3,151.4,149.5,148.9$, 126.7, 125.7, 125.2, 122.6, 119.8, 119.4, 117.7, 117.4, 117.1, 114.7, $114.3,109.8,109.3,101.7,101.5,28.6$; FAB (Neg.)-MS $m / z=497$ [M$\mathrm{H}]^{-1} ; 499[\mathrm{M}+2-\mathrm{H}]^{-1}$; ESI-MS $m / z=499[\mathrm{M}+\mathrm{H}]^{+}$; HRESI-MS Calcd for $\mathrm{C}_{25} \mathrm{H}_{13} \mathrm{ClF}_{2} \mathrm{O}_{7}[\mathrm{M}+\mathrm{H}]^{+}: m / z=499.0318$, Found 499.0336 .

\subsection{5 . 3,3'-((2", $4^{\prime \prime}-$ Dihydroxyphenyl)methylene)bis(6-fluoro-4-hydroxy- 2H-chromen-2-one) (13)}

White Solid; Yield: 81\%; M.p.: > $300{ }^{\circ} \mathrm{C}$ dec.; ${ }^{1} \mathrm{H}$ NMR $(300 \mathrm{MHz}$, Acetone- $d_{6}$ ): $\delta 7.84$ (dd, $\left.J_{5,7}=2.1 \mathrm{~Hz}, J_{5,6 \mathrm{~F}}=8.7 \mathrm{~Hz}, 1 \mathrm{H}, \mathrm{H}-5\right), 7.76(\mathrm{~d}$, $\left.J_{5^{\prime}, 7^{\prime}}=2.4 \mathrm{~Hz}, J_{5^{\prime}, 6 \mathrm{~F}}=8.7 \mathrm{~Hz}, 1 \mathrm{H}, \mathrm{H}-5^{\prime}\right), 7.52\left(\mathrm{~m}, 4 \mathrm{H}, \mathrm{H}-7, \mathrm{H}-8, \mathrm{H}-7^{\prime}\right.$, H- $8^{\prime}$ ), 7.10 (d, $\left.J_{6^{\prime \prime}, 5^{\prime \prime}}=8.4 \mathrm{~Hz}, 1 \mathrm{H}, \mathrm{H}-6^{\prime \prime}\right), 6.82$ (bd.s, $\left.1 \mathrm{H}, \mathrm{H}-3^{\prime \prime}\right), 6.65$ (m, $1 \mathrm{H}, \mathrm{H}-5^{\prime \prime}$ ), 5.62 (bd.s, $1 \mathrm{H},-\mathrm{CH}-$ ); ${ }^{13} \mathrm{C}$ NMR (75 MHz, DMSO- $d_{6}$ ): $\delta$ $160.2,159.9,159.5,157.3,156.7,156.3,148.5,148.3,129.1,119.9$, $119.6,119.5,119.2,118.7,118.6,118.4,118.3,115.0,114.9,113.1$, $111.9,108.6,108.3,102.9,28.2$; FAB (Neg.)-MS $m / z=461$ [M-H$\left.\mathrm{H}_{2} \mathrm{O}\right]^{-1}$; ESI-MS $m / z=463\left[\mathrm{M}+\mathrm{H}_{-} \mathrm{H}_{2} \mathrm{O}\right]^{+}$; HRESI-MS Calcd for $\mathrm{C}_{25} \mathrm{H}_{13} \mathrm{~F}_{2} \mathrm{O}_{7}\left[\mathrm{M}+\mathrm{H}-\mathrm{H}_{2} \mathrm{O}\right]^{+}: m / z=463.0629$, Found 463.0616 .

4.16. 3,3'-((3"'-Bromo-4''-methoxyphenyl)methylene)bis(6-fluoro-4hydroxy-2H-chromen-2-one) (14)

White Solid; Yield: $85 \%$; M.p.: $210-212{ }^{\circ} \mathrm{C}$; ${ }^{1} \mathrm{H}$ NMR $(300 \mathrm{MHz}$, Acetone- $d_{6}$ ): $\delta 11.47$ (s, $\left.2 \mathrm{H}, 2 \mathrm{OH}\right), 7.69$ (d, $J_{5,6 \mathrm{~F} / 5^{\prime}, 6 \mathrm{~F}}=8.7 \mathrm{~Hz}, 2 \mathrm{H}, \mathrm{H}-5$, H-5'), 7.54 (d, $\left.J_{7,8 / 8,7 / 7^{\prime}, 8^{\prime} / 8^{\prime}, 7^{\prime}}=6.6 \mathrm{~Hz}, 4 \mathrm{H}, \mathrm{H}-7, \mathrm{H}-8, \mathrm{H}-7^{\prime}, \mathrm{H}-8^{\prime}\right), 7.52$ (bd.s, $1 \mathrm{H}, \mathrm{H}-2^{\prime \prime}$ ), 7.32 (bd.d, $J_{6^{\prime \prime}, 5^{\prime \prime}}=8.1 \mathrm{~Hz}, 1 \mathrm{H}, \mathrm{H}-6^{\prime \prime}$ ), 7.02 (d, $\left.J_{5^{\prime \prime}, 6^{\prime \prime}}=8.4 \mathrm{~Hz}, 1 \mathrm{H}, \mathrm{H}-5^{\prime \prime}\right), 6.14(\mathrm{~s}, 1 \mathrm{H},-\mathrm{CH}-), 3.87$ (s, $\left.3 \mathrm{H}, \mathrm{OCH}_{3}\right) ;{ }^{13} \mathrm{C}$ NMR (75 MHz, DMSO- $\left.d_{6}\right): \delta 166.5,166.4,164.1,159.4,156.2,153.1$, 148.7, 135.4, 130.8, 127.2, 120.8, 120.7, 118.6, 118.2, 117.7, 117.6, 112.3, 110.0, 109.4, 109.1, 103.7, 56.1, 35.2; FAB (Neg.)-MS m/ $z=555[\mathrm{M}-\mathrm{H}]^{-1}, 557[\mathrm{M}+2-\mathrm{H}]^{-1}$; ESI-MS $m / z=557[\mathrm{M}+\mathrm{H}]^{+}$; HRESI-MS Calcd for $\mathrm{C}_{26} \mathrm{H}_{16} \mathrm{BrF}_{2} \mathrm{O}_{7}[\mathrm{M}+\mathrm{H}]^{+}: m / z=557.0047$, Found 557.0046 .

4.17. 3,3'-((4'-Bromo-2", $5^{\prime \prime}$-dimethoxyphenyl)methylene) bis(6-fluoro-4hydroxy-2H-chromen-2-one) (15)

White Solid; Yield: 83\%; M.p.: $205-207^{\circ} \mathrm{C}$; ${ }^{1} \mathrm{H}$ NMR $(300 \mathrm{MHz}$, Acetone- $d_{6}$ ): $\delta 11.30(\mathrm{~s}, 2 \mathrm{H}, 2 \mathrm{OH}), 7.67\left(\mathrm{~d}, J_{8,7 / 8^{\prime}, 7^{\prime}}=8.4 \mathrm{~Hz}, 2 \mathrm{H}, \mathrm{H}-8\right.$, $\left.\mathrm{H}-8^{\prime}\right), 7.49$ (d, $\left.J_{7,8 / 8,7 / 7^{\prime}, 8^{\prime} / 8^{\prime}, 7^{\prime}}=5.4 \mathrm{~Hz}, 4 \mathrm{H}, \mathrm{H}-7, \mathrm{H}-8, \mathrm{H}-7^{\prime}, \mathrm{H}-8^{\prime}\right), 7.14$ (s, $\left.1 \mathrm{H}, \mathrm{H}-3^{\prime \prime}\right), 7.10$ (s, $\left.1 \mathrm{H}, \mathrm{H}-6^{\prime \prime}\right), 6.13$ (s, $1 \mathrm{H},-\mathrm{CH}-$ ), 3.72 (s, $3 \mathrm{H}$, $\mathrm{OCH}_{3 \mathrm{~b}}$ ), 3.57 (s, 3H, $\mathrm{OCH}_{3 \mathrm{a}}$ ); ${ }^{13} \mathrm{C}$ NMR $\left(75 \mathrm{MHz}, \mathrm{DMSO}-\mathrm{d}_{6}\right): \delta 165.7$, $165.6,163.6,163.5,159.3,159.2,151.8,149.6,148.8,148.5,131.3$, $125.3,125.2,120.8,120.7,118.3,117.9,117.6,117.4,116.0,114.4$, 109.3, 109.0, 107.5, 104.0, 56.5, 56.5, 33.0; FAB (Neg.)-MS $m / z=586$ $[\mathrm{M}-\mathrm{H}]^{-1}, 588[\mathrm{M}+2-\mathrm{H}]^{-1}$; ESI-MS $m / z=587[\mathrm{M}+\mathrm{H}]^{+}, 589[\mathrm{M}$ $+2+\mathrm{H}]^{+}$; HRESI-MS Calcd for $\mathrm{C}_{27} \mathrm{H}_{18} \mathrm{BrF}_{2} \mathrm{O}_{8} \quad[\mathrm{M}+\mathrm{H}]^{+}: \mathrm{m} /$ $z=587.0153$, Found 587.0111.

\subsection{3,3'-((2", $3^{\prime \prime}-$ Dihydroxyphenyl)methylene)bis(4-hydroxy-2H- chromen-2-one) (16)}

White Solid; Yield: $82 \%$; M.p.: $110-112{ }^{\circ} \mathrm{C}$; ${ }^{1} \mathrm{H}$ NMR $(300 \mathrm{MHz}$, Acetone- $d_{6}$ ): $\delta 8.64$ (bd.s, $\left.1 \mathrm{H}, \mathrm{OH}\right), 8.36\left(\mathrm{~d}, J_{5,6}=8.1 \mathrm{~Hz}, 1 \mathrm{H}, \mathrm{H}-5\right)$, $8.06\left(\mathrm{~d}, J_{5^{\prime}, 6^{\prime}}=8.1 \mathrm{~Hz}, 1 \mathrm{H}, \mathrm{H}-5^{\prime}\right), 7.72\left(\mathrm{t}, J_{7,6}=J_{7,8}=8.4 \mathrm{~Hz}, 1 \mathrm{H}, \mathrm{H}-\right.$ 7), $\quad 7.61 \quad\left(\mathrm{t}, \quad J_{7^{\prime}, 6^{\prime}}=J_{7^{\prime}, 8^{\prime}}=7.2 \mathrm{~Hz}, \quad 1 \mathrm{H}, \quad \mathrm{H}-7^{\prime}\right), \quad 7.49 \quad(\mathrm{t}$, $\left.J_{6,5}=J_{6,7}=7.2 \mathrm{~Hz}, 1 \mathrm{H}, \mathrm{H}-6\right), 7.39\left(\mathrm{~d}, J_{8,7}=8.7 \mathrm{~Hz}, 1 \mathrm{H}, \mathrm{H}-8\right), 7.39(\mathrm{t}$, $\left.J_{6^{\prime}, 5^{\prime}}=J_{6^{\prime}, 7^{\prime}}=8.7 \mathrm{~Hz}, 1 \mathrm{H}, \mathrm{H}-6^{\prime}\right), 7.24\left(\mathrm{~d}, J_{8^{\prime}, 7^{\prime}}=8.1 \mathrm{~Hz}, 1 \mathrm{H}, \mathrm{H}-8^{\prime}\right), 6.98$ (t, $\left.J_{5^{\prime \prime}, 4^{\prime \prime}}=J_{5^{\prime \prime}, 6^{\prime \prime}}=7.8 \mathrm{~Hz}, 1 \mathrm{H}, \mathrm{H}-5^{\prime \prime}\right), 6.88\left(\mathrm{~d}, J_{6^{\prime \prime}, 5^{\prime \prime}}=6.6 \mathrm{~Hz}, 1 \mathrm{H}, \mathrm{H}-6^{\prime \prime}\right.$ ), $6.76\left(\mathrm{~d}, J_{4^{\prime \prime}, 5^{\prime \prime}}=7.5 \mathrm{~Hz}, 1 \mathrm{H}, \mathrm{H}-4^{\prime \prime}\right), 5.67$ (s, $1 \mathrm{H},-\mathrm{CH}-$ ); ${ }^{13} \mathrm{C}$ NMR (75 MHz, DMSO- $d_{6}$ ): $\delta 160.5,152.1,151.9,151.9,145.0,145.0,132.3$, $132.3,132.0,132.0,125.0,124.3,124.3,123.9,123.9,123.2,123.2$, $118.2,116.3,116.3,116.1,116.1,115.4,114.0,28.7$; FAB (Neg.)-MS $m / z=425\left[\mathrm{M}-\mathrm{H}-\mathrm{H}_{2} \mathrm{O}\right]^{-1}$; ESI-MS $m / z=427\left[\mathrm{M}+\mathrm{H}-\mathrm{H}_{2} \mathrm{O}\right]^{+}$; HRESIMS Calcd for $\mathrm{C}_{25} \mathrm{H}_{16} \mathrm{O}_{8}\left[\mathrm{M}+\mathrm{H}-\mathrm{H}_{2} \mathrm{O}\right]^{+}: m / z=427.0845$, Found 427.0868 .

4.19. $3,3^{\prime}-\left(\left(2^{\prime \prime}, 3^{\prime \prime}, 4^{\prime \prime}-\right.\right.$ Trihydroxyphenyl)methylene)bis(4-hydroxy-2Hchromen-2-one) (17)

White Solid; Yield: 77\%; M.p.: > $300{ }^{\circ} \mathrm{C}$ dec.; ${ }^{1} \mathrm{H}$ NMR $(300 \mathrm{MHz}$, Acetone- $d_{6}$ ): $\delta 8.36$ (d, $J_{5,6}=8.1 \mathrm{~Hz}, 1 \mathrm{H}, \mathrm{H}-5$ ), 8.36 (bd.s, $1 \mathrm{H}, \mathrm{OH}$ ), 8.08 (bd.s, $1 \mathrm{H}, \mathrm{OH}$ ), 8.05 (d, $\left.J_{5^{\prime}, 6^{\prime}}=6.6 \mathrm{~Hz}, 1 \mathrm{H}, \mathrm{H}-5^{\prime}\right), 7.72(\mathrm{t}$, $\left.J_{7,6}=J_{7,8}=8.7 \mathrm{~Hz}, 1 \mathrm{H}, \mathrm{H}-7\right), 7.60\left(\mathrm{t}, J_{7^{\prime}, 6^{\prime}}=J_{7^{\prime}, 8^{\prime}}=7.2 \mathrm{~Hz}, 1 \mathrm{H}, \mathrm{H}-7^{\prime}\right)$, $7.49\left(\mathrm{t}, J_{6,5}=J_{6,7}=7.2 \mathrm{~Hz}, 1 \mathrm{H}, \mathrm{H}-6\right), 7.40\left(\mathrm{~d}, J_{6^{n}, 5^{\prime \prime}}=8.7 \mathrm{~Hz}, 1 \mathrm{H}, \mathrm{H}-\right.$ $\left.6^{\prime \prime}\right), 7.38\left(\mathrm{t}, J_{6^{\prime}, 5^{\prime}}=J_{6^{\prime}, 7^{\prime}}=8.1 \mathrm{~Hz}, 1 \mathrm{H}, \mathrm{H}-6^{\prime}\right), 7.24\left(\mathrm{~d}, J_{5^{\prime \prime}, 6^{\prime \prime}}=8.1 \mathrm{~Hz}\right.$, $\left.1 \mathrm{H}, \mathrm{H}-5^{\prime \prime}\right), 6.66\left(\mathrm{~m}, 2 \mathrm{H}, \mathrm{H}-8, \mathrm{H}-8^{\prime}\right), 5.60(\mathrm{~s}, 1 \mathrm{H},-\mathrm{CH}-)$; ${ }^{13} \mathrm{C} \mathrm{NMR}$ $\left(100 \mathrm{MHz}\right.$, DMSO- $\left.d_{6}\right): \delta 160.5,160.5,156.1,152.0,152.0,151.8$, $151.8,145.5,145.5,138.7,132.9,132.9,132.2,131.9,124.3,124.3$, $123.8,123.4,117.3,116.2,116.1,114.1,112.2,28.3$; FAB (Neg.)-MS $m / z=441\left[\mathrm{M}-\mathrm{H}-\mathrm{H}_{2} \mathrm{O}\right]^{-1}$; ESI-MS $m / z=443\left[\mathrm{M}+\mathrm{H}-\mathrm{H}_{2} \mathrm{O}\right]^{+}$; HRESIMS Calcd for $\mathrm{C}_{25} \mathrm{H}_{15} \mathrm{O}_{8}\left[\mathrm{M}+\mathrm{H}-\mathrm{H}_{2} \mathrm{O}\right]^{+}: m / z=443.0766$, Found 443.0744.

4.20. 3,3'-((2", $3^{\prime \prime}-$ Dimethylphenyl)methylene) bis(4-hydroxy-2Hchromen-2-one) (18)

White Solid; Yield: 73\%; M.p.: 203-205 ${ }^{\circ}$; ${ }^{1} \mathrm{H}$ NMR $(300 \mathrm{MHz}$, DMSO- $d_{6}$ ): $\delta 7.81$ (d, $\left.J_{5,6 / 5^{\prime}, 6^{\prime}}=7.5 \mathrm{~Hz}, 2 \mathrm{H}, \mathrm{H}-5, \mathrm{H}-5^{\prime}\right), 7.49(\mathrm{t}$, $\left.J_{7,6}=J_{7,8}=J_{7^{\prime}, 6^{\prime}}=J_{7^{\prime}, 8^{\prime}}=6.9 \mathrm{~Hz}, 2 \mathrm{H}, \mathrm{H}-7, \quad \mathrm{H}-7^{\prime}\right), 7.24$ (d, $J_{8,7 /}$ $\left.8^{\prime}, 7^{\prime}=8.1 \mathrm{~Hz}, \quad 2 \mathrm{H}, \quad \mathrm{H}-8, \quad \mathrm{H}-8^{\prime}\right), \quad 7.24 \quad$ (t, $\left.J_{6,5}=J_{6,7}=J_{6^{\prime}, 5^{\prime}}=J_{6^{\prime}, 7^{\prime}}=8.1 \mathrm{~Hz}, \quad 2 \mathrm{H}, \quad \mathrm{H}-6, \quad \mathrm{H}-6^{\prime}\right), \quad 7.14 \quad(\mathrm{~d}$, $\left.J_{4^{\prime \prime}, 5^{\prime \prime}}=8.4 \mathrm{~Hz}, 1 \mathrm{H}, \mathrm{H}-4^{\prime \prime}\right), 6.80\left(\mathrm{~m}, 2 \mathrm{H}, \mathrm{H}-5^{\prime \prime}, \mathrm{H}-6^{\prime \prime}\right), 6.02$ (s, $1 \mathrm{H}$, $-\mathrm{CH}-$ ), 2.16 (s, 3H, $\mathrm{CH}_{3}$ ), 2.01 (s, $\left.1 \mathrm{H}, \mathrm{CH}_{3}\right) ;{ }^{13} \mathrm{C}$ NMR $(100 \mathrm{MHz}$, DMSO- $d_{6}$ ): $\delta 162.2,162.2,161.4,161.4,152.6,152.6,136.8,135.7$, $135.4,128.2$, 128.2, 127.5, 125.4, 125.3, 125.3, 123.4, 123.4, 121.4, $116.6,116.6,112.2,112.2,100.0,100.0,28.5,19.3,17.2$; FAB (Neg.)MS $m / z=439[\mathrm{M}-\mathrm{H}]^{-1}$; ESI-MS $m / z=441[\mathrm{M}+\mathrm{H}]^{+}$; HRESI-MS Calcd for $\mathrm{C}_{27} \mathrm{H}_{21} \mathrm{O}_{6}[\mathrm{M}+\mathrm{H}]^{+}: m / z=441.1338$, Found 441.1328.

\subsection{3,3'-((5'-Chloro-2'-hydroxyphenyl)methylene)bis(4-hydroxy-2H- chromen-2-one) (19)}

White Solid; Yield: 78\%; M.p.: $>300{ }^{\circ} \mathrm{C}$ dec.; ${ }^{1} \mathrm{H}$ NMR $(300 \mathrm{MHz}$, DMSO- $d_{6}$ ): $\delta 8.10$ (d, $\left.J_{5,6}=7.5 \mathrm{~Hz}, 1 \mathrm{H}, \mathrm{H}-5\right), 8.04$ (bd.d, $1 \mathrm{H}, \mathrm{H}-5^{\prime}$ ), $7.73\left(\mathrm{t}, J_{7,6}=J_{7,8}=8.7 \mathrm{~Hz}, 1 \mathrm{H}, \mathrm{H}-7\right), 7.62\left(\mathrm{t}, J_{7^{\prime}, 6^{\prime}}=J_{7^{\prime}, 8^{\prime}}=8.4 \mathrm{~Hz}\right.$, $1 \mathrm{H}, \mathrm{H}-7^{\prime}$ ), 7.51 (m, 6H, H-6, H-8, H-6', H-8', H-3', H-4'), 7.18 (s, 1H, H6"), 5.70 (bd.s, $1 \mathrm{H},-\mathrm{CH}-$ ); FAB (Neg.)-MS $m / z=461[\mathrm{M}-\mathrm{H}]^{-1}, 463$ $[\mathrm{M}+2-\mathrm{H}]^{-1}$; ESI-MS $m / z=445\left[\mathrm{M}+\mathrm{H}^{-\mathrm{H}_{2} \mathrm{O}}\right]^{+}$; HRESI-MS Calcd for $\mathrm{C}_{25} \mathrm{H}_{14} \mathrm{ClO}_{6}\left[\mathrm{M}+\mathrm{H}-\mathrm{H}_{2} \mathrm{O}\right]^{+}: m / z=445.0478$, Found 445.0453 .

\subsection{3,3'-((2", $4^{\prime \prime}-$ Dihydroxyphenyl)methylene)bis(4-hydroxy-2H-} chromen-2-one) (20)

White Solid; Yield: 82\%; M.p.: $>300{ }^{\circ} \mathrm{C}$ dec.; ${ }^{1} \mathrm{H}$ NMR $(300 \mathrm{MHz}$, DMSO- $d_{6}$ ): $\delta 9.68$ (s, $\left.1 \mathrm{H}, \mathrm{OH}\right), 8.07$ (d, $\left.J_{5,6}=6.9 \mathrm{~Hz}, 1 \mathrm{H}, \mathrm{H}-5\right), 7.95$ (bd.s, $1 \mathrm{H}, \mathrm{H}-5^{\prime}$ ), 7.69 (t, $J_{7,6}=J_{7,8}=7.2 \mathrm{~Hz}, 1 \mathrm{H}, \mathrm{H}-7$ ), $7.52(\mathrm{t}$, $\left.J_{7^{\prime}, 6^{\prime}}=J_{7^{\prime}, 8^{\prime}}=7.2 \mathrm{~Hz}, 1 \mathrm{H}, \mathrm{H}-7^{\prime}\right), 7.48\left(\mathrm{t}, J_{6,5}=J_{6,7}=8.1 \mathrm{~Hz}, 1 \mathrm{H}, \mathrm{H}-6\right)$, $7.43\left(\mathrm{~d}, J_{8,7}=7.5 \mathrm{~Hz}, 1 \mathrm{H}, \mathrm{H}-8\right), 7.25\left(\mathrm{~m}, 2 \mathrm{H}, \mathrm{H}-6^{\prime}, \mathrm{H}-8^{\prime}\right), 7.00(\mathrm{~d}$, $\left.J_{6^{\prime \prime}, 5^{\prime \prime}}=8.4 \mathrm{~Hz}, 1 \mathrm{H}, \mathrm{H}-6^{\prime \prime}\right), 6.67$ (d, $\left.J_{3^{\prime \prime}, 5^{\prime \prime}}=2.1 \mathrm{~Hz}, 1 \mathrm{H}, \mathrm{H}-3^{\prime \prime}\right), 6.55$ (dd, $\left.J_{5^{\prime \prime}, 3^{\prime \prime}}=2.1 \mathrm{~Hz}, J_{5^{\prime \prime}, 6^{\prime \prime}}=6.0 \mathrm{~Hz}, 1 \mathrm{H}, \mathrm{H}-5^{\prime \prime}\right), 5.57$ (s, $1 \mathrm{H},-\mathrm{CH}-$ ); FAB (Neg.)-MS $m / z=425 \quad\left[\mathrm{M}-\mathrm{H}_{-} \mathrm{H}_{2} \mathrm{O}\right]^{-1} ; \quad$ ESI-MS $m / z=427 \quad[\mathrm{M}+\mathrm{H}-$ $\left.\mathrm{H}_{2} \mathrm{O}\right]^{+}$; HRESI-MS Calcd for $\mathrm{C}_{25} \mathrm{H}_{15} \mathrm{O}_{7} \quad\left[\mathrm{M}+\mathrm{H}_{-} \mathrm{H}_{2} \mathrm{O}\right]^{+}: \quad m /$ $z=427.0817$, Found 427.0816. 
4.23. 3,3'-((3", $5^{\prime \prime}$-Dibromo-4-hydroxyphenyl)methylene)bis(4-hydroxy2H-chromen-2-one) (21)

White Solid; Yield: 87\%; M.p.: > $300{ }^{\circ} \mathrm{C} \mathrm{dec}$.; ${ }^{1} \mathrm{H}$ NMR $(300 \mathrm{MHz}$, DMSO- $d_{6}$ ): $\delta 7.82\left(\mathrm{~d}, J_{5,6 / 5^{\prime}, 6^{\prime}}=6.3 \mathrm{~Hz}, 2 \mathrm{H}, \mathrm{H}-5, \mathrm{H}-5^{\prime}\right), 7.53$ (t, $\left.J_{7,6}=J_{7,8}=J_{7^{\prime}, 6^{\prime}}=J_{7^{\prime}, 8^{\prime}}=6.9 \mathrm{~Hz}, 2 \mathrm{H}, \quad \mathrm{H}-7, \quad \mathrm{H}-7^{\prime}\right), 7.27$ (d, $J_{8,7 /}$ $\left.8^{\prime}, 7^{\prime}=8.1 \mathrm{~Hz}, 2 \mathrm{H}, \mathrm{H}-8, \mathrm{H}-8^{\prime}\right), 7.26$ (t, $J_{6,5}=J_{6,7}=J_{6^{\prime}, 5^{\prime}}=J_{6^{\prime}, 7^{\prime}}=$ $7.5 \mathrm{~Hz}, 2 \mathrm{H}, \mathrm{H}-6, \mathrm{H}-6^{\prime}$ ), 7.12 (bd.s, 2H, H-2", H-6"), 6.16 (s, 1H, -CH-); ${ }^{13} \mathrm{C}$ NMR (75 MHz, DMSO- $d_{6}$ ): $\delta 167.2,167.2,164.2,164.2,152.4$, 152.4, 148.1, 148.1, 136.6, 131.3, 131.3, 130.2, 130.2, 124.0, 124.0, 123.1, 123.1, 119.3, 119.3, 115.6, 115.6, 111.7, 102.9, 102.9, 35.0; FAB (Neg.)-MS $m / z=584[\mathrm{M}-\mathrm{H}]^{-1} 586[\mathrm{M}+2-\mathrm{H}]^{-1}$; ESI-MS $m /$ $z=585[\mathrm{M}+\mathrm{H}]^{+} 587[\mathrm{M}+2+\mathrm{H}]^{+} 589[\mathrm{M}+4+\mathrm{H}]^{+}$; HRESI-MS Calcd for $\mathrm{C}_{25} \mathrm{H}_{15} \mathrm{Br}_{2} \mathrm{O}_{7}[\mathrm{M}+\mathrm{H}]^{+}: m / z=584.9184$, Found 584.9208 .

\subsection{4. $3,3^{\prime}-\left(\left(3^{\prime \prime}, 5^{\prime \prime}-\right.\right.$ Dichlorophenyl)methylene)bis(4-hydroxy-2H-} chromen-2-one) (22)

White Solid; Yield: 82\%; M.p.: $232-234{ }^{\circ} \mathrm{C} ;{ }^{1} \mathrm{H}$ NMR $(300 \mathrm{MHz}$, Acetone- $d_{6}$ ): $\delta 8.14$ (d, $\left.J_{5,6}=6.3 \mathrm{~Hz}, 1 \mathrm{H}, \mathrm{H}-5\right), 8.08$ (d, $J_{5^{\prime}, 6^{\prime}}=6.6 \mathrm{~Hz}$, $\left.1 \mathrm{H}, \quad \mathrm{H}-5^{\prime}\right), \quad 7.76$ (t, $\left.J_{7,6}=J_{7,8}=8.4 \mathrm{~Hz}, 1 \mathrm{H}, \quad \mathrm{H}-7\right), 7.62 \quad(\mathrm{t}$, $\left.J_{7^{\prime}, 6^{\prime}}=J_{7^{\prime}, 8^{\prime}}=7.5 \mathrm{~Hz}, 1 \mathrm{H}, \mathrm{H}-7^{\prime}\right), 7.55\left(\mathrm{t}, J_{6,5}=J_{6,7}=7.5 \mathrm{~Hz}, 1 \mathrm{H}, \mathrm{H}-6\right)$, $7.52 \quad\left(\mathrm{~d}, \quad J_{2^{\prime \prime}, 6^{\prime \prime} / 6^{\prime \prime}, 2^{\prime \prime}}=2.4 \mathrm{~Hz}, \quad 1 \mathrm{H}, \quad \mathrm{H}-2^{\prime \prime}, \quad \mathrm{H}-6^{\prime \prime}\right), \quad 7.43 \quad(\mathrm{t}$, $\left.J_{6^{\prime}, 5^{\prime}}=J_{6^{\prime}, 7^{\prime}}=8.4 \mathrm{~Hz}, 1 \mathrm{H}, \mathrm{H}-6^{\prime}\right), 7.38\left(\mathrm{~d}, J_{8,7}=7.2 \mathrm{~Hz}, 1 \mathrm{H}, \mathrm{H}-8\right), 7.32$ $\left(\mathrm{d}, J_{4^{\prime \prime}, 2^{\prime \prime} / 4^{\prime \prime}, 6^{\prime \prime}}=2.4 \mathrm{~Hz}, 1 \mathrm{H}, \mathrm{H}-4^{\prime \prime}\right), 7.27$ (d, $\left.J_{8^{\prime}, 7^{\prime}}=8.1 \mathrm{~Hz}, 1 \mathrm{H}, \mathrm{H}-8^{\prime}\right)$, 5.74 (s, $1 \mathrm{H},-\mathrm{CH}-) ;{ }^{13} \mathrm{C}$ NMR $\left(100 \mathrm{MHz}\right.$, DMSO-d $\left.{ }_{6}\right): \delta 162.7,162.7$, 161.6, 161.6, 152.4, 152.4, 145.2, 135.7, 135.7, 128.4, 128.4, 126.8, $126.8,126.3,125.3,125.3,123.4,123.4,116.5,116.5,116.3,116.3$, 100.1, 100.1, 28.4; FAB (Neg.)-MS $m / z=476[\mathrm{M}-\mathrm{H}]^{-1}, 478[\mathrm{M}+2-$ $\mathrm{H}]^{-1}$; ESI-MS $m / z=479[\mathrm{M}+\mathrm{H}]^{+}, 481[\mathrm{M}+2+\mathrm{H}]^{+}$; HRESI-MS Calcd for $\mathrm{C}_{25} \mathrm{H}_{15} \mathrm{Cl}_{2} \mathrm{O}_{6}[\mathrm{M}+\mathrm{H}]^{+}: m / z=479.0089$, Found 479.0105 .

\subsection{5 . 3,3'-((2", $5^{\prime \prime}-$ Dimethoxyphenyl)methylene)bis(4-hydroxy-2H-} chromen-2-one) (23)

White Solid; Yield: 74\%; M.p.: $181-183{ }^{\circ} \mathrm{C}$; ${ }^{1} \mathrm{H}$ NMR $(300 \mathrm{MHz}$, DMSO- $d_{6}$ ): $\delta 7.87$ (dd, $J_{5,7 / 5^{\prime}, 7^{\prime}}=1.2 \mathrm{~Hz}, J_{5,6 / 5^{\prime}, 6^{\prime}}=6.6 \mathrm{~Hz}, 2 \mathrm{H}, \mathrm{H}-5, \mathrm{H}-$ $\left.5^{\prime}\right), 7.56\left(\mathrm{t}, J_{7,6}=J_{7,8}=J_{7^{\prime}, 6^{\prime}}=J_{7^{\prime}, 8^{\prime}}=8.4 \mathrm{~Hz}, 2 \mathrm{H}, \mathrm{H}-7, \mathrm{H}-7^{\prime}\right), 7.31$ (d, $\left.J_{8,7 / 8^{\prime}, 7^{\prime}}=7.8 \mathrm{~Hz}, 2 \mathrm{H}, \mathrm{H}-8, \mathrm{H}-8^{\prime}\right), 7.30\left(\mathrm{t}, J_{6,7}=J_{6,8}=J_{6^{\prime}, 7^{\prime}}=J_{6^{\prime}, 8^{\prime}}=\right.$ $\left.7.5 \mathrm{~Hz}, 2 \mathrm{H}, \mathrm{H}-6, \mathrm{H}-6^{\prime}\right), 6.79\left(\mathrm{~d}, J_{4^{\prime \prime}, 3^{\prime \prime}}=8.4 \mathrm{~Hz}, 1 \mathrm{H}, \mathrm{H}-4^{\prime \prime}\right), 6.71(\mathrm{~s}, 1 \mathrm{H}$, H-6"), 6.71 (d, $\left.J_{3^{\prime \prime}, 4^{\prime \prime}}=8.7 \mathrm{~Hz}, 1 \mathrm{H}, \mathrm{H}-3^{\prime \prime}\right), 6.19$ (s, $1 \mathrm{H},-\mathrm{CH}-$ ), 3.60 (s, $\left.3 \mathrm{H}, \mathrm{OCH}_{3 \mathrm{a}}\right), 3.48\left(\mathrm{~s}, 3 \mathrm{H}, \mathrm{OCH}_{3 \mathrm{~b}}\right) ;{ }^{13} \mathrm{C}$ NMR $\left(75 \mathrm{MHz}, \mathrm{DMSO}-d_{6}\right): \delta$ $165.1,163.9,152.7,152.1,151.6,131.1,131.1,123.7,123.7,123.2$, 123.2 , 118.5, 116.2, 115.6, 115.6, 111.8, 109.6, 104.2, 56.1, 55.0, 32.9; FAB (Neg.)-MS $m / z=470[\mathrm{M}-\mathrm{H}]^{-1}$; ESI-MS $m / z=473[\mathrm{M}$ $+\mathrm{H}]^{+}$; HRESI-MS Calcd for $\mathrm{C}_{27} \mathrm{H}_{20} \mathrm{O}_{8}[\mathrm{M}+\mathrm{H}]^{+}: m / z=473.1236$, Found 473.1198.

\subsection{6. $3,3^{\prime}-\left(\left(2^{\prime \prime}, 3^{\prime \prime}-\right.\right.$ Dimethoxyphenyl)methylene)bis(4-hydroxy-2H-} chromen-2-one) (24)

White Solid; Yield: 76\%; M.p.: $190-192{ }^{\circ} \mathrm{C} ;{ }^{1} \mathrm{H}$ NMR $(300 \mathrm{MHz}$, DMSO- $d_{6}$ ): $\delta 7.85$ (dd, $J_{5,7 / 5^{\prime}, 7^{\prime}}=1.2 \mathrm{~Hz}, J_{5,6 / 5^{\prime}, 6^{\prime}}=6.9 \mathrm{~Hz}, 2 \mathrm{H}, \mathrm{H}-5, \mathrm{H}-$ $5^{\prime}$ ),7.53 (t, $J_{7,6}=J_{7,8}=J_{7^{\prime}, 6^{\prime}}=J_{7^{\prime}, 8^{\prime}}=8.4 \mathrm{~Hz}, 2 \mathrm{H}, \mathrm{H}-7, \mathrm{H}-7^{\prime}$ ), 7.28 (d, $\left.J_{8,7 / 8^{\prime}, 7^{\prime}}=8.4 \mathrm{~Hz}, 2 \mathrm{H}, \mathrm{H}-8, \mathrm{H}-8^{\prime}\right), 7.27\left(\mathrm{t}, J_{6,7}=J_{6,8}=J_{6^{\prime}, 7^{\prime}}=J_{6^{\prime}, 8^{\prime}}=\right.$ $7.5 \mathrm{~Hz}, 2 \mathrm{H}, \mathrm{H}-6, \mathrm{H}-6^{\prime}$ ), 6.89 (m, 3H, H-4", H-5", H-6"), 6.29 (s, 1H, $-\mathrm{CH}-$ ), 3.71 (s, $3 \mathrm{H}, \mathrm{OCH}_{3 \mathrm{~b}}$ ), $3.44\left(\mathrm{~s}, 3 \mathrm{H}, \mathrm{OCH}_{3 \mathrm{a}}\right) ;{ }^{13} \mathrm{C} \mathrm{NMR}(75 \mathrm{MHz}$, DMSO- $\left.d_{6}\right): \delta 165.0,164.0,152.2,152.0,146.5,135.1,131.2,131.2$, 123.7, 123.7, 123.3, 123.3, 122.5, 120.8, 118.5, 115.7, 115.7, 110.7,

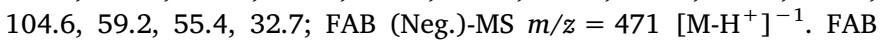
(Neg.)-MS $m / z=471[\mathrm{M}-\mathrm{H}]^{-1}$; ESI-MS $m / z=473[\mathrm{M}+\mathrm{H}]^{+}$; HRESIMS Calcd for $\mathrm{C}_{27} \mathrm{H}_{21} \mathrm{O}_{8}[\mathrm{M}+\mathrm{H}]^{+}: m / z=473.1236$, Found 473.1207 .
4.27. 3,3'-((4'-Ethoxy-3''-methoxyphenyl)methylene)bis(4-hydroxy-2Hchromen-2-one) (25)

White Solid; Yield: $78 \%$; M.p.: $195-197^{\circ} \mathrm{C}$; ${ }^{1} \mathrm{H}$ NMR $(300 \mathrm{MHz}$, DMSO- $d_{6}$ ): $\delta 7.81\left(\mathrm{dd}, J_{5,7 / 5^{\prime}, 7^{\prime}}=1.5 \mathrm{~Hz}, J_{5,6 / 5^{\prime}, 6^{\prime}}=6.3 \mathrm{~Hz}, 2 \mathrm{H}, \mathrm{H}-5, \mathrm{H}-\right.$ $5^{\prime}$ ), 7.50 (t, $J_{7,6}=J_{7,8}=J_{7^{\prime}, 6^{\prime}}=J_{7^{\prime}, 8^{\prime}}=6.9 \mathrm{~Hz}, 2 \mathrm{H}, \mathrm{H}-7, \mathrm{H}-7^{\prime}$ ), 7.25 (d, $\left.J_{8,7 / 8^{\prime}, 7^{\prime}}=8.1 \mathrm{~Hz}, 2 \mathrm{H}, \mathrm{H}-8, \mathrm{H}-8^{\prime}\right), 7.23$ (t, $J_{6,7}=J_{6,8}=J_{6^{\prime}, 7^{\prime}}=J_{6^{\prime}, 8^{\prime}}=$ $7.2 \mathrm{~Hz}, 2 \mathrm{H}, \mathrm{H}-6, \mathrm{H}-6^{\prime}$ ), 6.73 (d, $\left.J_{5^{\prime \prime}, 6^{\prime \prime}}=8.7 \mathrm{~Hz}, 1 \mathrm{H}, \mathrm{H}-5^{\prime \prime}\right), 6.64$ (s, $1 \mathrm{H}$, $\left.\mathrm{H}-2^{\prime \prime}\right), 6.60$ (d, $\left.J_{6^{\prime \prime}, 5^{\prime \prime}}=8.7 \mathrm{~Hz}, 1 \mathrm{H}, \mathrm{H}-6^{\prime \prime}\right), 6.18$ (s, $\left.1 \mathrm{H},-\mathrm{CH}-\right), 3.92$ (q, $2 \mathrm{H}, \mathrm{OCH}_{2}-$ ), $3.50\left(\mathrm{~s}, 3 \mathrm{H}, \mathrm{OCH}_{3}\right), 1.29$ (t, 3H, $\mathrm{CH}_{3}$ ); FAB (Neg.)-MS m/ $z=485[\mathrm{M}-\mathrm{H}]^{-1}$; ESI-MS $m / z=487[\mathrm{M}+\mathrm{H}]^{+}$; HRESI-MS Calcd for $\mathrm{C}_{28} \mathrm{H}_{23} \mathrm{O}_{8}[\mathrm{M}+\mathrm{H}]^{+}: m / z=487.1392$, Found 487.1385.

4.28. 3,3'-((2", 4'-Dimethoxyphenyl)methylene)bis(4-hydroxy-2Hchromen-2-one) (26)

White Solid; Yield: 72\%; M.p.: 197-199 ${ }^{\circ}$; ${ }^{1} \mathrm{H}$ NMR $(300 \mathrm{MHz}$, DMSO- $\left.d_{6}\right): \delta 7.82\left(\mathrm{~d}, J_{5,6 / 5^{\prime}, 6^{\prime}}=6.9 \mathrm{~Hz}, 2 \mathrm{H}, \mathrm{H}-5, \mathrm{H}-5^{\prime}\right), 7.50(\mathrm{t}$, $\left.J_{7,6}=J_{7,8}=J_{7^{\prime}, 6^{\prime}}=J_{7^{\prime}, 8^{\prime}}=8.4 \mathrm{~Hz}, 2 \mathrm{H}, \quad \mathrm{H}-7, \quad \mathrm{H}-7^{\prime}\right), 7.25$ (d, $J_{8,7 /}$ $\left.8^{\prime}, 7^{\prime}=8.1 \mathrm{~Hz}, \quad 2 \mathrm{H}, \quad \mathrm{H}-8, \quad \mathrm{H}-8^{\prime}\right), 7.22 \quad\left(\mathrm{t}, \quad J_{6,7}=J_{6,8}=J_{6^{\prime}, 7^{\prime}}=J_{6^{\prime}, 8^{\prime}}=\right.$ $\left.7.8 \mathrm{~Hz}, 2 \mathrm{H}, \mathrm{H}-6, \mathrm{H}-6^{\prime}\right), 7.06$ (d, $\left.J_{6^{\prime \prime}, 5^{\prime \prime}}=8.1 \mathrm{~Hz}, 1 \mathrm{H}, \mathrm{H}-6^{\prime \prime}\right), 6.39$ (m, $2 \mathrm{H}$, H-3", H-5"), 6.12 (s, $1 \mathrm{H},-\mathrm{CH}-$ ), 3.68 (s, 3H, $\mathrm{OCH}_{3 \mathrm{~b}}$ ), 1.29 (t, 3H, $\left.\mathrm{OCH}_{3 \mathrm{a}}\right) ;{ }^{13} \mathrm{C}$ NMR $\left(100 \mathrm{MHz}\right.$, DMSO- $\left.d_{6}\right): \delta 164.4,163.9,158.8,158.0$, 152.0, 131.2, 131.2, 128.7, 123.6, 123.6, 123.3, 123.3, 120.9, 118.2, 115.7, 115.7, 104.6, 103.8, 98.5, 55.5, 55.0, 32.2; FAB (Neg.)-MS $m /$ $z=470[\mathrm{M}-\mathrm{H}]^{-1}$; ESI-MS $m / z=473[\mathrm{M}+\mathrm{H}]^{+}$; HRESI-MS Calcd for $\mathrm{C}_{27} \mathrm{H}_{21} \mathrm{O}_{8}[\mathrm{M}+\mathrm{H}]^{+}: m / z=473.1236$, Found 473.1230.

4.29. 3,3'-((4"'-Bromo-2'-fluorophenyl)methylene)bis(4-hydroxy-2Hchromen-2-one) (27)

White Solid; Yield: 83\%; M.p.: $245-247^{\circ} \mathrm{C}$; ${ }^{1} \mathrm{H}$ NMR $(300 \mathrm{MHz}$, DMSO- $d_{6}$ ): $\delta 7.81$ (d, $\left.J_{5,6 / 5^{\prime}, 6^{\prime}}=6.6 \mathrm{~Hz}, 2 \mathrm{H}, \mathrm{H}-5, \mathrm{H}-5^{\prime}\right), 7.52(\mathrm{t}$, $\left.J_{7,6}=J_{7,8}=J_{7^{\prime}, 6^{\prime}}=J_{7^{\prime}, 8^{\prime}}=8.4 \mathrm{~Hz}, 2 \mathrm{H}, \mathrm{H}-7, \mathrm{H}-7^{\prime}\right), 7.27$ (m, 7H, H-6, H8, H-6', H-8', H-3", H-5", H-6"), 6.24 (s, $1 \mathrm{H},-\mathrm{CH}-$ ); ${ }^{13} \mathrm{C}$ NMR $\left(100 \mathrm{MHz}, \mathrm{DMSO}-d_{6}\right): \delta 162.9,162.5,162.2,160.4,160.0,151.4$, $150.9,132.6,128.4,127.2,125.7,125.2,121.5,120.5,119.8,119.4$, $117.7,117.4,114.7,114.3,109.8,109.3,101.7,101.5,28.6$; FAB (Neg.)-MS $m / z=507[\mathrm{M}-\mathrm{H}]^{-1} 509[\mathrm{M}+2-\mathrm{H}]^{-1}$; ESI-MS $m / z=509$ $[\mathrm{M}+\mathrm{H}]^{+} 511[\mathrm{M}+2+\mathrm{H}]^{+}$; HRESI-MS Calcd for $\mathrm{C}_{25} \mathrm{H}_{15} \mathrm{BrFO}_{6}[\mathrm{M}$ $+\mathrm{H}]^{+}: m / z=509.0036$, Found 509.0032.

4.30. 3,3'-((2"-Bromo-4", $5^{\prime \prime}$-dimethoxyphenyl)methylene)bis(4-hydroxy2H-chromen-2-one) (28)

White Solid; Yield: $85 \%$; M.p.: $200-202{ }^{\circ} \mathrm{C} ;{ }^{1} \mathrm{H}$ NMR $(300 \mathrm{MHz}$, DMSO- $d_{6}$ ): $\delta 7.83\left(\mathrm{~d}, J_{5,6 / 5^{\prime}, 6^{\prime}}=6.6 \mathrm{~Hz}, 2 \mathrm{H}, \mathrm{H}-5, \mathrm{H}-5^{\prime}\right), 7.26(\mathrm{t}$, $\left.J_{7,6}=J_{7,8}=J_{7^{\prime}, 6^{\prime}}=J_{7^{\prime}, 8^{\prime}}=7.2 \mathrm{~Hz}, 2 \mathrm{H}, \quad \mathrm{H}-7, \quad \mathrm{H}-7^{\prime}\right), 7.26$ (d, $J_{8,7 /}$ $\left.8^{\prime}, 7^{\prime}=8.7 \mathrm{~Hz}, 2 \mathrm{H}, \mathrm{H}-8, \quad \mathrm{H}-8^{\prime}\right), 7.25$ (t, $J_{6,7}=J_{6,8}=J_{6^{\prime}, 7^{\prime}}=J_{6^{\prime}, 8^{\prime}}=$ $8.1 \mathrm{~Hz}, 2 \mathrm{H}, \mathrm{H}-6, \mathrm{H}-6^{\prime}$ ), 7.01 (s, 1H, H-3"), 6.97 (s, 1H, H-6"), 5.97 (s, $1 \mathrm{H},-\mathrm{CH}-), 3.70\left(\mathrm{~s}, 3 \mathrm{H}, \mathrm{OCH}_{3 \mathrm{a}}\right), 1.29\left(\mathrm{t}, 3 \mathrm{H}, \mathrm{OCH}_{3 \mathrm{~b}}\right) ;{ }^{13} \mathrm{C} \mathrm{NMR}$ $\left(100 \mathrm{MHz}, \mathrm{DMSO}-d_{6}\right): \delta 190.1,165.3,163.5,152.2,147.6,147.1$, 133.0, 131.2, 131.2, 123.7, 123.7, 123.3, 123.3, 118.4, 116.0, 115.7, 115.7, 114.4, 113.4, 110.5, 104.1, 55.7, 55.6, 37.9; FAB (Neg.)-MS m/ $z=549[\mathrm{M}-\mathrm{H}]^{-1}, 551[\mathrm{M}+2-\mathrm{H}]^{-1} ;$ ESI-MS $m / z=551[\mathrm{M}+\mathrm{H}]^{+}, 553$ $[\mathrm{M}+2+\mathrm{H}]^{+}$; HRESI-MS Calcd for $\mathrm{C}_{27} \mathrm{H}_{20} \mathrm{BrO}_{8}[\mathrm{M}+\mathrm{H}]^{+}: \mathrm{m} /$ $z=551.0341$, Found 551.0327.

4.31. 3,3'-((3'-(Benzyloxy)-4"-methoxyphenyl)methylene)bis(4hydroxy-2H-chromen-2-one) (29)

White Solid; Yield: $81 \%$; M.p.: $210-212{ }^{\circ} \mathrm{C} ;{ }^{1} \mathrm{H}$ NMR $(300 \mathrm{MHz}$, Acetone- $d_{6}$ ): $\delta 11.44$ (s, $\left.1 \mathrm{H}, \mathrm{OH}\right), 8.01$ (d, $J_{5,6 / 5^{\prime}, 6^{\prime}}=6.9 \mathrm{~Hz}, 2 \mathrm{H}, \mathrm{H}-5, \mathrm{H}-$ $5^{\prime}$ ), $7.74\left(\mathrm{t}, J_{7,6}=J_{7,8}=J_{7^{\prime}, 6^{\prime}}=J_{7^{\prime}, 8^{\prime}}=7.2 \mathrm{~Hz}, 2 \mathrm{H}, \mathrm{H}-7, \mathrm{H}-7^{\prime}\right), 7.48$ (t, $\left.J_{6,7}=J_{6,8}=J_{6^{\prime}, 7^{\prime}}=J_{6^{\prime}, 8^{\prime}}=8.1 \mathrm{~Hz}, 2 \mathrm{H}, \mathrm{H}-6, \quad \mathrm{H}-6^{\prime}\right), 7.48$ (d, $J_{8,7 /}$ $\left.8^{\prime}, 7^{\prime}=7.8 \mathrm{~Hz}, 2 \mathrm{H}, \mathrm{H}-8, \mathrm{H}-8^{\prime}\right), 7.26$ (m, 2H, H-2'", H-6"'), 7.20 (m, 3H, H- 
3"', H-4"', H-6"'), 6.97 (bd.s, 1H, H-2"'), 6.93 (d, $J_{6^{\prime \prime}, 5^{\prime \prime}}=7.2 \mathrm{~Hz}, 1 \mathrm{H}, \mathrm{H}-$ $\left.6^{\prime \prime}\right), 6.87\left(\mathrm{~d}, J_{5^{\prime \prime}, 6^{\prime \prime}}=7.2 \mathrm{~Hz}, 1 \mathrm{H}, \mathrm{H}-5^{\prime \prime}\right), 6.04(\mathrm{~s}, 1 \mathrm{H},-\mathrm{CH}-), 4.96(\mathrm{~s}, 2 \mathrm{H}$, $-\mathrm{CH}-$ ), $3.80\left(\mathrm{~s}, 3 \mathrm{H}, \mathrm{OCH}_{3}\right) ;{ }^{13} \mathrm{C}$ NMR $\left(100 \mathrm{MHz}, \mathrm{DMSO}-d_{6}\right): \delta 162.9$, $162.9,161.7,161.7,152.6,152.6,149.8,146.6,136.5,135.7,128.7$, $128.7,128.4,128.4,127.4,127.2,127.2,125.5,125.5,123.2,123.2$, 122.4, 116.7, 116.7, 116.2, 116.2, 114.2, 112.4, 100.4, 100.4, 71.2, 28.7, 56.2; FAB (Neg.)-MS $m / z=546[\mathrm{M}-\mathrm{H}]^{-1}$; ESI-MS $m / z=549[\mathrm{M}$ $+\mathrm{H}]^{+}$; HRESI-MS Calcd for $\mathrm{C}_{33} \mathrm{H}_{25} \mathrm{O}_{8}[\mathrm{M}+\mathrm{H}]^{+}: m / z=549.1549$, Found 549.1550.

4.32. 3,3'-((4'-Hydroxy-3"'-methoxyphenyl)methylene)bis(4-hydroxy2H-chromen-2-one) (30)

White Solid; Yield: 84\%; M.p.: $255-257{ }^{\circ} \mathrm{C}$; ${ }^{1} \mathrm{H}$ NMR $(300 \mathrm{MHz}$, Acetone- $\left.d_{6}\right): \delta 11.45(\mathrm{~s}, 2 \mathrm{H}, 2 \mathrm{OH}), 8.02\left(\mathrm{~d}, J_{5,6 / 5^{\prime}, 6^{\prime}}=7.2 \mathrm{~Hz}, 2 \mathrm{H}, \mathrm{H}-5\right.$, H-5'), 7.75 (t, $J_{7,6}=J_{7,8}=J_{7^{\prime}, 6^{\prime}}=J_{7^{\prime}, 8^{\prime}}=7.5 \mathrm{~Hz}, 2 \mathrm{H}, \mathrm{H}-7, \mathrm{H}-7^{\prime}$ ), 7.51 (m, 4H, H-6, H-8, H-6', H-8'), 6.95 (s, 1H, H-2"), 6.77 (s, 2H, H-5', H$\left.6^{\prime \prime}\right), 6.08$ (s, $1 \mathrm{H},-\mathrm{CH}-$ ), 3.67 (s, 3H, $\mathrm{OCH}_{3}$ ); FAB (Neg.)-MS $m / z=457$ $[\mathrm{M}-\mathrm{H}]^{-1}$; ESI-MS $m / z=459[\mathrm{M}+\mathrm{H}]^{+}$; HRESI-MS Calcd for $\mathrm{C}_{26} \mathrm{H}_{19} \mathrm{O}_{8}$ $[\mathrm{M}+\mathrm{H}]^{+}: m / z=459.1079$, Found 459.1053 .

\subsection{3,3'-((4"'-(Methylthio)phenyl)methylene)bis(4-hydroxy-2H-} chromen-2-one) (31)

White Solid; Yield: 77\%; M.p.: $260-262{ }^{\circ} \mathrm{C} ;{ }^{1} \mathrm{H}$ NMR $(300 \mathrm{MHz}$, Acetone- $d_{6}$ ): $\delta 11.50$ (s, $\left.2 \mathrm{H}, 2 \mathrm{OH}\right), 8.03$ (d, $J_{5,6 / 5^{\prime}, 6^{\prime}}=8.4 \mathrm{~Hz}, 2 \mathrm{H}, \mathrm{H}-5$, H-5'), 7.76 (t, $J_{7,6}=J_{7,8}=J_{7^{\prime}, 6^{\prime}}=J_{7^{\prime}, 8^{\prime}}=6.9 \mathrm{~Hz}, 2 \mathrm{H}, \mathrm{H}-7, \mathrm{H}-7^{\prime}$ ), 7.49 (m, 4H, H-6, H-8, H-6', H-8'), 7.29 (d, $J_{2^{\prime \prime}, 3^{\prime \prime} / 6^{\prime \prime}, 5^{\prime \prime}}=8.1 \mathrm{~Hz}, 2 \mathrm{H}, \mathrm{H}-2^{\prime \prime}, \mathrm{H}-$ $\left.6^{\prime \prime}\right), 7.23\left(\mathrm{~d}, J_{3^{\prime \prime}, 2^{\prime \prime} / 5^{\prime \prime}, 6^{\prime \prime}}=8.7 \mathrm{~Hz}, 2 \mathrm{H}, \mathrm{H}-3^{\prime \prime}, \mathrm{H}-5^{\prime \prime}\right), 6.10$ (s, $1 \mathrm{H},-\mathrm{CH}-$ ),

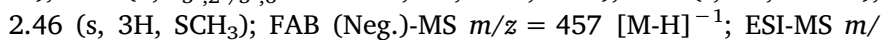
$z=459[\mathrm{M}+\mathrm{H}]^{+}$; HRESI-MS Calcd for $\mathrm{C}_{26} \mathrm{H}_{19} \mathrm{O}_{6} \mathrm{~S}[\mathrm{M}+\mathrm{H}]^{+}: \mathrm{m} /$ $z=459.0902$, Found 459.0922 .

4.34. 3,3'-((3"'-Bromo-4"'-methoxyphenyl)methylene)bis(6-chloro-4hydroxy-2H-chromen-2-one) (32)

White Solid; Yield: 85\%; M.p.: 204-206 ${ }^{\circ} \mathrm{C}$; ${ }^{1} \mathrm{H}$ NMR $(300 \mathrm{MHz}$, DMSO- $d_{6}$ ): $\delta 7.73$ (d, $J_{5,7 / 5^{\prime}, 7^{\prime}}=2.4 \mathrm{~Hz}, 2 \mathrm{H}, \mathrm{H}-5, \mathrm{H}-5^{\prime}$ ), 7.55 (dd, $J_{7,5}$, $\left.7^{\prime}, 5^{\prime}=2.4 \mathrm{~Hz}, \quad J_{7,8 / 7^{\prime}, 8^{\prime}}=9.0 \mathrm{~Hz}, \quad 2 \mathrm{H}, \quad \mathrm{H}-7, \quad \mathrm{H}-7^{\prime}\right), \quad 7.32$ (d, $J_{8,7 /}$ $8^{\prime}, 7^{\prime}=8.7 \mathrm{~Hz}, 2 \mathrm{H}, \mathrm{H}-8, \mathrm{H}-8^{\prime}$ ), 7.15 (bd.s, $1 \mathrm{H}, \mathrm{H}-2^{\prime \prime}$ ), 7.04 (bd.d, $\left.J_{6^{\prime \prime}, 5^{\prime \prime}}=8.4 \mathrm{~Hz}, 1 \mathrm{H}, \mathrm{H}-6^{\prime \prime}\right), 6.92\left(\mathrm{~d}, J_{5^{\prime \prime}, 6^{\prime \prime}}=8.7 \mathrm{~Hz}, 1 \mathrm{H}, \mathrm{H}-5^{\prime \prime}\right), 6.15$ (s, $1 \mathrm{H},-\mathrm{CH}-), 3.76\left(\mathrm{~s}, 3 \mathrm{H}, \mathrm{OCH}_{3}\right) ;{ }^{13} \mathrm{C}$ NMR $\left(100 \mathrm{MHz}, \mathrm{DMSO}-d_{6}\right): \delta$ $166.3,163.9,153.1,151.0,135.3,130.8,130.8,130.7,127.2$, 127.2, $123.2,123.2,121.1,117.7,117.7,112.3,110.0,103.8,56.0,32.2$; FAB (Neg.)-MS $m / z=587[\mathrm{M}-\mathrm{H}]^{-1} ; 589[\mathrm{M}+2-\mathrm{H}]^{-1} ; 591[\mathrm{M}+4-\mathrm{H}]^{-1}$; ESI-MS $m / z=599[\mathrm{M}+\mathrm{H}]^{+}$; HRESI-MS Calcd for $\mathrm{C}_{26} \mathrm{H}_{15} \mathrm{BrCl}_{2} \mathrm{O}_{7}[\mathrm{M}$ $+\mathrm{H}]^{+}: m / z=588.9456$, Found 588.9479.

4.35 . 3,3'-((3'-(Benzyloxy)phenyl)methylene)bis(6-chloro-4-hydroxy2H-chromen-2-one) (33)

White Solid; Yield: $80 \%$; M.p.: $192-194{ }^{\circ} \mathrm{C}$; ${ }^{1} \mathrm{H}$ NMR $(300 \mathrm{MHz}$, DMSO- $d_{6}$ ): $\delta 7.72$ (d, $J_{5,7 / 5^{\prime}, 7^{\prime}}=2.4 \mathrm{~Hz}, 2 \mathrm{H}, \mathrm{H}-5, \mathrm{H}-5^{\prime}$ ), 7.54 (dd, $J_{7,5}$ / $\left.7^{\prime}, 5^{\prime}=2.4 \mathrm{~Hz}, J_{7,8 / 7^{\prime}, 8^{\prime}}=6.3 \mathrm{~Hz}, 2 \mathrm{H}, \mathrm{H}-7, \mathrm{H}-7^{\prime}\right), 7.31$ (m, $4 \mathrm{H}, \mathrm{H}-8, \mathrm{H}-8^{\prime}$, $\left.\mathrm{H}-3^{\prime \prime \prime}, \quad \mathrm{H}-5^{\prime \prime \prime}\right), \quad 7.24$ (m, 3H, H-2"', H-4"', H-6"'), 7.09 (t, $\left.J_{5^{\prime \prime}, 4^{\prime \prime}}=J_{5^{\prime \prime}, 6^{\prime \prime}}=8.1 \mathrm{~Hz}, 1 \mathrm{H}, \mathrm{H}-5^{\prime \prime}\right), 6.74\left(\mathrm{~d}, J_{6^{\prime \prime}, 5^{\prime \prime}}=8.1 \mathrm{~Hz}, 1 \mathrm{H}, \mathrm{H}-6^{\prime \prime}\right)$, 6.64 (m, 2H, H-2", H-4"), 6.18 (s, $1 \mathrm{H},-\mathrm{CH}-$ ), $4.94\left(\mathrm{~s}, 3 \mathrm{H}, \mathrm{OCH}_{2}\right) ;{ }^{13} \mathrm{C}$ NMR (75 MHz, DMSO- $\left.d_{6}\right): \delta 166.1,166.1,164.0,164.0,158.3,151.0$, $151.0,143.2$, 137.2, 130.8, 130.8, 128.8, 128.2, 128.2, 127.7, 127.6, 127.6, 127.2, 127.2, 123.2, 123.2, 121.1, 119.3, 119.3, 117.7, 117.7, $113.7,110.9,104.0,104.0,69.1,36.2$; FAB (Neg.)-MS $m / z=585$ [M$\mathrm{H}]^{-1}, 587[\mathrm{M}+2-\mathrm{H}]^{-1}$; ESI-MS $m / z=587[\mathrm{M}+\mathrm{H}]^{+}$; HRESI-MS Calcd for $\mathrm{C}_{32} \mathrm{H}_{21} \mathrm{Cl}_{2} \mathrm{O}_{7}[\mathrm{M}+\mathrm{H}]^{+}: m / z=587.0664$, Found 587.0666.
4.36. $3,3^{\prime}-\left(\left(2^{\prime \prime}, 3^{\prime \prime}, 4^{\prime \prime}-\right.\right.$ Trihydroxyphenyl)methylene)bis(6-chloro-4hydroxy-2H-chromen-2-one) (34)

White Solid; Yield: 86\%; M.p.: $>300{ }^{\circ} \mathrm{C} \mathrm{dec} . ;{ }^{1} \mathrm{H}$ NMR $(300 \mathrm{MHz}$, DMSO-d $d_{6}$ ): $\delta 9.26$ (bd.s, 1H, OH), 9.06 (bd.s, 1H, OH), 8.56 (d, $J_{5,7}=2.7 \mathrm{~Hz}, 2 \mathrm{H}, \mathrm{H}-5$ ), 7.95 (bd.s, $1 \mathrm{H}, \mathrm{H}-5^{\prime}$ ), 7.72 (d, $J_{7,8}=8.7 \mathrm{~Hz}$, $1 \mathrm{H}, \mathrm{H}-7$ ), 7.58 (d, $\left.J_{7^{\prime}, 8^{\prime}}=9.0 \mathrm{~Hz}, 1 \mathrm{H}, \mathrm{H}-7^{\prime}\right), 7.47\left(\mathrm{~d}, J_{8,7}=9.0 \mathrm{~Hz}, 1 \mathrm{H}\right.$, H-8), 7.31 (d, $\left.J_{8^{\prime}, 7^{\prime}}=8.4 \mathrm{~Hz}, 1 \mathrm{H}, \mathrm{H}-8^{\prime}\right), 6.55$ (d, $J_{6^{\prime \prime}, 5^{\prime \prime}}=8.4 \mathrm{~Hz}, 1 \mathrm{H}, \mathrm{H}-$ $\left.6^{\prime \prime}\right), 6.46\left(\mathrm{~d}, J_{5^{\prime \prime}, 6^{\prime \prime}}=8.4 \mathrm{~Hz}, 1 \mathrm{H}, \mathrm{H}-5^{\prime \prime}\right), 5.56(\mathrm{~s}, 1 \mathrm{H},-\mathrm{CH}-) ;{ }^{13} \mathrm{C} \mathrm{NMR}$ $\left(100 \mathrm{MHz}\right.$, DMSO- $\left.d_{6}\right): \delta 166.0,165.7,164.1,163.6,151.4,151.0$, 148.6, 147.4, 133.9, 131.3, 130.9, 129.5, 129.2, 126.7, 126.4, 124.5, $122.9,122.5,118.9,118.6,116.7,100.5,100.2,108.6,30.6$; FAB (Neg.)-MS $m / z=509 \quad\left[\mathrm{M}-\mathrm{H}_{-} \mathrm{H}_{2} \mathrm{O}\right]^{-1} ; \quad$ ESI-MS $m / z=511 \quad[\mathrm{M}+\mathrm{H}-$ $\left.\mathrm{H}_{2} \mathrm{O}\right]^{+}$; HRESI-MS Calcd for $\mathrm{C}_{25} \mathrm{H}_{14} \mathrm{Cl}_{2} \mathrm{O}_{9} \quad\left[\mathrm{M}+\mathrm{H}_{-}-\mathrm{H}_{2} \mathrm{O}\right]^{+}: \mathrm{m} /$ $z=511.0093$, Found 511.0062.

4.37. 3,3'-((3",5'-Dibromo-4"'-hydroxyphenyl)methylene)bis(6-chloro-4hydroxy-2H-chromen-2-one) (35)

White Solid; Yield: 82\%; M.p.: $>300{ }^{\circ} \mathrm{C} \mathrm{dec} . ;{ }^{1} \mathrm{H}$ NMR $(300 \mathrm{MHz}$, DMSO- $d_{6}$ ): $\delta 7.74$ (d, $J_{5,7 / 5^{\prime}, 7^{\prime}}=2.4 \mathrm{~Hz}, 2 \mathrm{H}, \mathrm{H}-5, \mathrm{H}-5^{\prime}$ ), 7.55 (dd, $J_{7,5}$ / $\left.7^{\prime}, 5^{\prime}=2.4 \mathrm{~Hz}, \quad J_{7,8 / 7^{\prime}, 8^{\prime}}=6.3 \mathrm{~Hz}, \quad 2 \mathrm{H}, \quad \mathrm{H}-7, \quad \mathrm{H}-7^{\prime}\right), \quad 7.32$ (d, $J_{8,7 /}$ $\left.8^{\prime}, 7^{\prime}=8.7 \mathrm{~Hz}, 2 \mathrm{H}, \mathrm{H}-8, \mathrm{H}-8^{\prime}\right), 7.13\left(\mathrm{~s}, 2 \mathrm{H}, \mathrm{H}-2^{\prime \prime}, \mathrm{H}-6^{\prime \prime}\right), 6.13$ (s, $1 \mathrm{H}$, $-\mathrm{CH}-) ;{ }^{13} \mathrm{C}$ NMR $\left(100 \mathrm{MHz}\right.$, DMSO- $\left.d_{6}\right): \delta 166.4,166.4,164.3,164.3$, $151.3,150.8,150.8,139.0,134.5,134.5,131.0,131.0,129.5,129.5$, $126.8,126.8,122.9,122.9,118.8,118.8,110.3,110.3,100.2,100.2$,

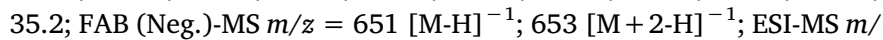
$z=653[\mathrm{M}+\mathrm{H}]^{+}$; HRESI-MS Calcd for $\mathrm{C}_{25} \mathrm{H}_{12} \mathrm{Br}_{2} \mathrm{Cl}_{2} \mathrm{O}_{7}[\mathrm{M}+\mathrm{H}]^{+}: \mathrm{m} /$ $z=652.8405$, Found 652.8436 .

4.38. 3,3'-((2"'-Hydroxynaphthalen-1'"-yl)methylene)bis(6-chloro-4hydroxy-2H-chromen-2-one) (36)

White Solid; Yield: $86 \%$; M.p.: $252-254{ }^{\circ} \mathrm{C}$; ${ }^{1} \mathrm{H}$ NMR $(300 \mathrm{MHz}$, DMSO- $d_{6}$ ): $\delta 10.83(\mathrm{~s}, 2 \mathrm{H}, 2 \mathrm{OH}), 9.13(\mathrm{~s}, 1 \mathrm{H}, \mathrm{OH}), 8.66\left(\mathrm{~d}, J_{5^{\prime \prime}, 6^{\prime \prime} /}\right.$ $\left.8^{\prime \prime}, 7^{\prime \prime}=8.4 \mathrm{~Hz}, 2 \mathrm{H}, \mathrm{H}-5^{\prime \prime}, \mathrm{H}-8^{\prime \prime}\right), 8.32$ (d, $\left.J_{4^{\prime \prime}}, 3^{\prime \prime}=9.3 \mathrm{~Hz}, 1 \mathrm{H}, \mathrm{H}-4^{\prime \prime}\right), 8.11$ (d, $\left.J_{3^{\prime \prime}, 4^{\prime \prime}}=7.8 \mathrm{~Hz}, 1 \mathrm{H}, \mathrm{H}-3^{\prime \prime}\right), 7.79\left(\mathrm{t}, J_{6^{\prime \prime}, 5^{\prime \prime}}=J_{6^{\prime \prime}, 7^{\prime \prime}}=7.5 \mathrm{~Hz}, 1 \mathrm{H}, \mathrm{H}-6^{\prime \prime}\right)$, 7.67 (m, 4H, $-\mathrm{CH}-$, H-5, H-5', H-7'), 7.51 (dd, $J_{7,5 / 7^{\prime}, 5^{\prime}}=2.4 \mathrm{~Hz}, J_{7,8}$ / $\left.7^{\prime}, 8^{\prime}=8.7 \mathrm{~Hz}, 2 \mathrm{H}, \mathrm{H}-7, \mathrm{H}-7^{\prime}\right), 6.94$ (d, $\left.J_{8,7 / 8^{\prime} 7^{\prime}}=8.7 \mathrm{~Hz}, 2 \mathrm{H}, \mathrm{H}-8, \mathrm{H}-8^{\prime}\right)$; ${ }^{13} \mathrm{C}$ NMR (75 MHz, DMSO- $d_{6}$ ): $\delta 190.4,158.1,156.9,154.3,139.6$, 139.6, 135.1, 135.1, 134.2, 134.2, 129.9, 129.4, 129.4, 129.2, 129.0, $129.0,128.8,128.8,127.5,126.4,125.7,122.9,122.5,122.5,118.9$, $118.9, \quad 116.5, \quad 112.7, \quad 28.6 ; \quad$ FAB $\quad$ (Neg.)-MS $m / z=440 \quad$ [M$\left.\mathrm{H}-2 \mathrm{H}_{2} \mathrm{O}-2 \mathrm{Cl}\right]^{-1}$; ESI-MS $m / z=529\left[\mathrm{M}+\mathrm{H}-\mathrm{H}_{2} \mathrm{O}\right]^{+}$; HRESI-MS Calcd for $\mathrm{C}_{29} \mathrm{H}_{16} \mathrm{Cl}_{2} \mathrm{O}_{7}\left[\mathrm{M}+\mathrm{H}-\mathrm{H}_{2} \mathrm{O}\right]^{+}: m / z=529.0245$, Found 529.0268 .

4.39. 3,3'-((4'-Hydroxy-3"'-iodo-5"'-methoxyphenyl)methylene)bis(6chloro-4-hydroxy-2H-chromen-2-one) (37)

White Solid; Yield: $80 \%$; M.p.: $234-236{ }^{\circ} \mathrm{C} ;{ }^{1} \mathrm{H}$ NMR $(300 \mathrm{MHz}$, DMSO- $d_{6}$ ): $\delta 7.74$ (d, $J_{5,7 / 5^{\prime}, 7^{\prime}}=2.7 \mathrm{~Hz}, 2 \mathrm{H}, \mathrm{H}-5, \mathrm{H}-5^{\prime}$ ), 7.54 (dd, $J_{7,5 /}$ $\left.7^{\prime}, 5^{\prime}=2.7 \mathrm{~Hz}, \quad J_{7,8 / 7^{\prime}, 8^{\prime}}=6.3 \mathrm{~Hz}, \quad 2 \mathrm{H}, \quad \mathrm{H}-7, \quad \mathrm{H}-7^{\prime}\right), \quad 7.31$ (d, $J_{8,7 /}$ $8^{\prime}, 7^{\prime}=9.0 \mathrm{~Hz}, 2 \mathrm{H}, \mathrm{H}-8, \mathrm{H}-8^{\prime}$ ), 6.90 (bd.s, $1 \mathrm{H}, \mathrm{H}-2^{\prime \prime}$ ), 6.64 (bd.s, $1 \mathrm{H}, \mathrm{H}-$ $\left.6^{\prime \prime}\right), 6.12(\mathrm{~s}, 1 \mathrm{H},-\mathrm{CH}-), 3.57$ (s, 3H, $\left.\mathrm{OCH}_{3}\right) ;{ }^{13} \mathrm{C}$ NMR (75 MHz, DMSO$\left.d_{6}\right): \delta 166.1,166.1,163.8,163.8,150.9,150.9,146.7,143.9,134.4$, $130.7,130.7,127.8,127.8,127.2,127.2,123.1,123.1,121.0,117.7$, $117.7,111.2,104.0,104.0,84.1,55.9,35.4 ;$ FAB (Neg.)-MS $m / z=651$ $[\mathrm{M}-\mathrm{H}]^{-1}, 653[\mathrm{M}+2-\mathrm{H}]^{-1}$; ESI-MS $m / z=653[\mathrm{M}+\mathrm{H}]^{+}$; HRESI-MS Calcd for $\mathrm{C}_{26} \mathrm{H}_{16} \mathrm{Cl}_{2} \mathrm{IO}_{8}[\mathrm{M}+\mathrm{H}]^{+}: m / z=652.9267$, Found 652.9280 .

4.40. 3,3'-((5'-Bromo-2"'-methoxyphenyl)methylene)bis(6-chloro-4hydroxy-2H-chromen-2-one) (38)

White Solid; Yield: 81\%; M.p.: 251-253 ${ }^{\circ} \mathrm{C}$; ${ }^{1} \mathrm{H}$ NMR $(300 \mathrm{MHz}$, DMSO- $d_{6}$ ): $\delta 7.73$ (d, $J_{5,7 / 5^{\prime}, 7^{\prime}}=2.4 \mathrm{~Hz}, 2 \mathrm{H}, \mathrm{H}-5, \mathrm{H}-5^{\prime}$ ), 7.52 (dd, $J_{7,5}$, $\left.7^{\prime}, 5^{\prime}=2.7 \mathrm{~Hz}, \quad J_{7,8 / 7^{\prime}, 8^{\prime}}=6.0 \mathrm{~Hz}, \quad 2 \mathrm{H}, \quad \mathrm{H}-7, \quad \mathrm{H}-7^{\prime}\right), \quad 7.29$ (d, $J_{8,7 /}$ 
$\left.8^{\prime}, 7^{\prime}=8.7 \mathrm{~Hz}, 2 \mathrm{H}, \mathrm{H}-8, \mathrm{H}-8^{\prime}\right), 7.23\left(\mathrm{~d}, J_{3^{\prime \prime}, 4^{\prime \prime}}=6.9 \mathrm{~Hz}, 1 \mathrm{H}, \mathrm{H}-3^{\prime \prime}\right), 7.21(\mathrm{~s}$, $\left.1 \mathrm{H}, \mathrm{H}-6^{\prime \prime}\right), 6.80$ (d, $\left.J_{4^{\prime \prime}, 3^{\prime \prime}}=8.4 \mathrm{~Hz}, 1 \mathrm{H}, \mathrm{H}-4^{\prime \prime}\right), 6.15$ (s, $1 \mathrm{H},-\mathrm{CH}-$ ), 3.53 (s, $\left.1 \mathrm{H}, \mathrm{OCH}_{3}\right) ;{ }^{13} \mathrm{C}$ NMR $\left(100 \mathrm{MHz}\right.$, DMSO- $\left.d_{6}\right): \delta 166.2,166.0,163.7$, 163.5, 157.7, 150.7, 150.5, 134.6, 131.2, 131.0, 129.8, 129.6, 126.7, $126.5,129.4,118.8,118.6,115.5,113.6,100.3,100.1,123.4,122.8$, $122.6,56.2,29.7$; FAB (Neg.)-MS $m / z=587[\mathrm{M}-\mathrm{H}]^{-1}, 589[\mathrm{M}+2$ $\mathrm{H}]^{-1}, 591[\mathrm{M}+4-\mathrm{H}]^{-1}$; ESI-MS $m / z=599[\mathrm{M}+\mathrm{H}]^{+}$; HRESI-MS Calcd for $\mathrm{C}_{26} \mathrm{H}_{15} \mathrm{BrCl}_{2} \mathrm{O}_{7}[\mathrm{M}+\mathrm{H}]^{+}: m / z=588.9456$, Found 588.9478 .

4.41. 3,3'-((2", $5^{\prime \prime}-$ Dihydroxyphenyl)methylene)bis(6-chloro-4-hydroxy2H-chromen-2-one) (39)

White Solid; Yield: 76\%; M.p.: $274-276{ }^{\circ} \mathrm{C}$; ${ }^{1} \mathrm{H}$ NMR $(300 \mathrm{MHz}$, DMSO- $d_{6}$ ): $\delta 9.37$ (s, $\left.1 \mathrm{H}, \mathrm{OH}\right), 8.07\left(\mathrm{~d}, J_{5,7}=2.1 \mathrm{~Hz}, 1 \mathrm{H}, \mathrm{H}-5\right), 8.00$ (bd.s, $1 \mathrm{H}, \mathrm{H}-5^{\prime}$ ), 7.74 (dd, $J_{7,5}=2.4 \mathrm{~Hz}, J_{7,8}=6.3 \mathrm{~Hz}, 1 \mathrm{H}, \mathrm{H}-7$ ), 7.62 (d, $\left.J_{7^{\prime}, 8^{\prime}}=7.5 \mathrm{~Hz}, 1 \mathrm{H}, \mathrm{H}-7^{\prime}\right), 7.49$ (d, $\left.J_{8,7}=8.7 \mathrm{~Hz}, 1 \mathrm{H}, \mathrm{H}-8\right), 7.35$ (d, $\left.J_{8^{\prime}, 7^{\prime}}=8.7 \mathrm{~Hz}, 1 \mathrm{H}, \mathrm{H}-8^{\prime}\right), 7.21\left(\mathrm{~d}, J_{3^{n}, 4^{\prime \prime}}=8.7 \mathrm{~Hz}, 1 \mathrm{H}, \mathrm{H}-3^{\prime \prime}\right), 6.67(\mathrm{~d}$, $J_{4^{\prime \prime}, 3^{\prime \prime}}=6.0 \mathrm{~Hz}, 1 \mathrm{H}, \mathrm{H}-4^{\prime \prime}$ ), 6.58 (bd.s, $1 \mathrm{H}, \mathrm{H}-6^{\prime \prime}$ ), 5.62 (bd.s, $1 \mathrm{H}$, $-\mathrm{CH}-) ;{ }^{13} \mathrm{C}$ NMR $\left(100 \mathrm{MHz}\right.$, DMSO- $\left.d_{6}\right): \delta 166.2,165.9,164.3,164.0$, $151.3,151.0,149.2,148.7,131.4,131.1,129.3,129.0,126.5,126.2$, 124.3, 122.7, 122.5, 118.7, 118.4, 117.2, 116.7, 114.6, 104.6, 104.3, 30.1; FAB (Neg.)-MS $m / z=493\left[\mathrm{M}-\mathrm{H}_{-} \mathrm{H}_{2} \mathrm{O}\right]^{-1} ; 495[\mathrm{M}+2-\mathrm{H}]^{-1}$; ESIMS $m / z=495[\mathrm{M}+\mathrm{H}]^{+}$; HRESI-MS Calcd for $\mathrm{C}_{25} \mathrm{H}_{14} \mathrm{Cl}_{2} \mathrm{O}_{8}[\mathrm{M}+\mathrm{H}]^{+}$: $m / z=495.0038$, Found 495.0065.

4.42. 3,3'-((3"'-Bromo-4"-hydroxyphenyl)methylene)bis(6-chloro-4hydroxy-2H-chromen-2-one) (40)

White Solid; Yield: $75 \%$; M.p.: $248-250{ }^{\circ} \mathrm{C}$; ${ }^{1} \mathrm{H}$ NMR $(300 \mathrm{MHz}$, DMSO- $d_{6}$ ): $\delta 9.84$ (bd.s, $2 \mathrm{H}, 2 \mathrm{OH}$ ), 7.73 (d, $J_{5,7 / 5^{\prime}, 7^{\prime}}=2.4 \mathrm{~Hz}, 2 \mathrm{H}, \mathrm{H}-5$, H-5'), 7.55 (dd, $J_{7,5 / 7^{\prime}, 5^{\prime}}=2.7 \mathrm{~Hz}, J_{7,8 / 7^{\prime}, 8^{\prime}}=6.0 \mathrm{~Hz}, 2 \mathrm{H}, \mathrm{H}-7, \mathrm{H}-7^{\prime}$ ), 7.31 (d, $\left.J_{8,7 / 8^{\prime}, 7^{\prime}}=8.7 \mathrm{~Hz}, 2 \mathrm{H}, \mathrm{H}-8, \mathrm{H}-8^{\prime}\right), 7.06$ (bd.s, $\left.1 \mathrm{H}, \mathrm{H}-2^{\prime \prime}\right), 6.88$ (d, $\left.J_{6^{\prime \prime}, 5^{\prime \prime}}=8.7 \mathrm{~Hz}, 1 \mathrm{H}, \mathrm{H}-6^{\prime \prime}\right), 6.76\left(\mathrm{~d}, J_{5^{\prime \prime}, 6^{\prime \prime}}=8.4 \mathrm{~Hz}, 1 \mathrm{H}, \mathrm{H}-5^{\prime \prime}\right), 6.11(\mathrm{~s}$, $1 \mathrm{H},-\mathrm{CH}-)$; ${ }^{13} \mathrm{C}$ NMR $\left(100 \mathrm{MHz}\right.$, DMSO- $\left.d_{6}\right): \delta 166.1,166.1,163.9$, $163.9,151.5,151.5,151.0,133.5,133.5,130.8,130.5,127.2,127.2$, $127.1,123.2,123.2,121.0,121.0,117.7,117.7,116.0,108.7,103.9$, 103.9, 35.2; FAB (Neg.)-MS $m / z=573[\mathrm{M}-\mathrm{H}]^{-1}, 575[\mathrm{M}+2-\mathrm{H}]^{-1}$; ESI-MS $m / z=575[\mathrm{M}+\mathrm{H}]^{+}$; HRESI-MS Calcd for $\mathrm{C}_{25} \mathrm{H}_{13} \mathrm{BrCl}_{2} \mathrm{O}_{7}[\mathrm{M}$ $+\mathrm{H}]^{+}: m / z=574.9300$, Found 574.9326.

4.43. 3,3'-((2"'-Bromo-5"-fluorophenyl)methylene)bis(6-chloro-4hydroxy-2H-chromen-2-one) (41)

White Solid; Yield: 79\%; M.p.: 273-275 ${ }^{\circ} \mathrm{C}$; ${ }^{1} \mathrm{H}$ NMR $(300 \mathrm{MHz}$, DMSO- $d_{6}$ ): $\delta 7.74$ (d, $J_{5,7 / 5^{\prime}, 7^{\prime}}=2.4 \mathrm{~Hz}, 2 \mathrm{H}, \mathrm{H}-5, \mathrm{H}-5^{\prime}$ ), 7.55 (dd, $J_{7,5}$ / $\left.7^{\prime}, 5^{\prime}=2.7 \mathrm{~Hz}, J_{7,8 / 7^{\prime}, 8^{\prime}}=6.0 \mathrm{~Hz}, 2 \mathrm{H}, \mathrm{H}-7, \mathrm{H}-7^{\prime}\right), 7.49$ (m, $\left.1 \mathrm{H}, \mathrm{H}-3^{\prime \prime}\right)$, $7.31\left(\mathrm{~d}, J_{8,7 / 8^{\prime}, 7^{\prime}}=8.7 \mathrm{~Hz}, 2 \mathrm{H}, \mathrm{H}-8, \mathrm{H}-8^{\prime}\right), 7.11\left(\mathrm{dd}, J_{6^{\prime \prime}, 4^{\prime \prime \prime}}=3.0 \mathrm{~Hz}\right.$, $\left.J_{6^{\prime \prime}, \mathrm{F}}=7.8 \mathrm{~Hz}, 1 \mathrm{H}, \mathrm{H}-6^{\prime \prime}\right), 6.99\left(\mathrm{~m}, 1 \mathrm{H}, \mathrm{H}-4^{\prime \prime}\right), 5.97$ (s, $\left.1 \mathrm{H},-\mathrm{CH}-\right) ;{ }^{13} \mathrm{C}$ NMR (100 MHz, DMSO- $d_{6}$ ): $\delta 166.0,166.0,163.4,163.4,161.6,150.9$, 150.9, 142.4, 133.2, 131.4, 131.4, 129.7, 129.7, 126.8, 126.8, 122.7, $122.7,119.3,118.7,118.7,118.6,114.5,104.2,104.2,31.8$; FAB (Neg.)-MS $m / z=574[\mathrm{M}-\mathrm{H}]^{-1}, 576[\mathrm{M}+2-\mathrm{H}]^{-1}, 578[\mathrm{M}+4-\mathrm{H}]^{-1}$; ESI-MS $m / z=579[\mathrm{M}+\mathrm{H}]^{+}$; HRESI-MS Calcd for $\mathrm{C}_{25} \mathrm{H}_{13} \mathrm{BrCl}_{2} \mathrm{FO}_{6}[\mathrm{M}$ $+\mathrm{H}]^{+}: m / z=576.9256$, Found 576.9296 .

4.44. 3,3'-((4"'-Bromo-3", $5^{\prime \prime}$-dimethoxyphenyl)methylene)bis(6-chloro-4hydroxy-2H-chromen-2-one) (42)

White Solid; Yield: 82\%; M.p.: 276-278 ${ }^{\circ} \mathrm{C}$; ${ }^{1} \mathrm{H}$ NMR $(300 \mathrm{MHz}$, DMSO- $d_{6}$ ): $\delta 7.74$ (d, $J_{5,7 / 5^{\prime}, 7^{\prime}}=2.4 \mathrm{~Hz}, 2 \mathrm{H}, \mathrm{H}-5, \mathrm{H}-5^{\prime}$ ), 7.54 (dd, $J_{7,5 /}$ $\left.7^{\prime}, 5^{\prime}=2.7 \mathrm{~Hz}, \quad J_{7,8 / 7^{\prime}, 8^{\prime}}=6.3 \mathrm{~Hz}, \quad 2 \mathrm{H}, \quad \mathrm{H}-7, \quad \mathrm{H}-7^{\prime}\right), \quad 7.31$ (d, $J_{8,7 /}$ $\left.8^{\prime}, 7^{\prime}=8.7 \mathrm{~Hz}, 2 \mathrm{H}, \mathrm{H}-8, \mathrm{H}-8^{\prime}\right), 6.45\left(\mathrm{~s}, 2 \mathrm{H}, \mathrm{H}-2^{\prime \prime}, \mathrm{H}-6^{\prime \prime}\right), 6.19(\mathrm{~s}, 1 \mathrm{H}$, $-\mathrm{CH}-$ ), 3.58 (s, $\left.6 \mathrm{H}, 2 \mathrm{OCH}_{3}\right) ;{ }^{13} \mathrm{C}$ NMR $\left(100 \mathrm{MHz}, \mathrm{DMSO}-\mathrm{d}_{6}\right): \delta 160.0$, $160.0,159.2$, 159.2, 155.2, 155.2, 150.6, 150.6, 149.7, 132.2, 132.2, 131.8, 131.8, 129.1, 129.1, 128.7, 128.0, 118.6, 118.6, 117.7, 117.7, $112.2,112.2,101.5,55.5,55.5,28.2$; FAB (Neg.)-MS $m / z=617[\mathrm{M}-$
$\mathrm{H}]^{-1}, 619[\mathrm{M}+2-\mathrm{H}]^{-1}, 621[\mathrm{M}+4-\mathrm{H}]^{-1}$; ESI-MS $m / z=619[\mathrm{M}$ $+\mathrm{H}]^{+}$; HRESI-MS Calcd for $\mathrm{C}_{27} \mathrm{H}_{17} \mathrm{BrCl}_{2} \mathrm{O}_{8} \quad[\mathrm{M}+\mathrm{H}]^{+}: \mathrm{m} /$ $z=618.9562$, Found 618.9536.

4.45. 3,3'-((2'-Fluoro-4"-methoxyphenyl)methylene)bis(6-chloro-4hydroxy-2H-chromen-2-one) (43)

White Solid; Yield: $75 \%$; M.p.: $243-245{ }^{\circ} \mathrm{C}$; ${ }^{1} \mathrm{H}$ NMR $(300 \mathrm{MHz}$, DMSO- $d_{6}$ ): $\delta 8.13$ (d, $J_{5,7}=2.4 \mathrm{~Hz}, 1 \mathrm{H}, \mathrm{H}-5$ ), 7.99 (bd.s, $1 \mathrm{H}, \mathrm{H}-5^{\prime}$ ), 7.74 (dd, $J_{7,5}=2.8 \mathrm{~Hz}, J_{7,8}=6.0 \mathrm{~Hz}, 1 \mathrm{H}, \mathrm{H}-7$ ), 7.60 (bd.d, $J_{7^{\prime}, 8^{\prime}}=7.2 \mathrm{~Hz}$, $1 \mathrm{H}, \mathrm{H}-7^{\prime}$ ), 7.50 (d, $\left.J_{8,7}=8.8 \mathrm{~Hz}, 1 \mathrm{H}, \mathrm{H}-8\right), 7.33$ (d, $J_{8^{\prime}, 7^{\prime}}=9.2 \mathrm{~Hz}, 1 \mathrm{H}$, H-8'), 7.08 (d, $\left.J_{6^{\prime \prime}, 5^{\prime \prime}}=8.4 \mathrm{~Hz}, 1 \mathrm{H}, \mathrm{H}-6^{\prime \prime}\right), 7.03\left(\mathrm{~d}, J_{3^{\prime \prime}, 5^{\prime \prime}}=2.4 \mathrm{~Hz}, 1 \mathrm{H}, \mathrm{H}-\right.$ $3^{\prime \prime}$ ), 6.73 (dd, $J_{5^{\prime \prime}, 3^{\prime \prime}}=2.4 \mathrm{~Hz}, J_{5^{\prime \prime}, 6^{\prime \prime}}=6.3 \mathrm{~Hz}, 1 \mathrm{H}, \mathrm{H}-5^{\prime \prime}$ ), 5.61 (bd.s, $1 \mathrm{H}$, - $\mathrm{CH}-$ ), 3.77 (s, $\left.1 \mathrm{H}, \mathrm{OCH}_{3}\right) ;{ }^{13} \mathrm{C}$ NMR $\left(75 \mathrm{MHz}\right.$, DMSO- $\left.d_{6}\right): \delta 166.0$, $166.0,163.8,163.8,155.9,151.0,151.0,143.0,131.2,131.2,130.8$, $130.8,127.2,127.2,123.1,123.1,120.8,118.3,117.8,117.8,104.0$, 104.0, 103.9, 96.7, 56.0, 36.7; FAB (Neg.)-MS $m / z=527[\mathrm{M}-\mathrm{H}]^{-1}, 529$ $[\mathrm{M}+2-\mathrm{H}]^{-1}$; ESI-MS $m / z=529[\mathrm{M}+\mathrm{H}]^{+}$; HRESI-MS Calcd for $\mathrm{C}_{26} \mathrm{H}_{15} \mathrm{Cl}_{2} \mathrm{FO}_{7}[\mathrm{M}+\mathrm{H}]^{+}: m / z=529.0257$, Found 529.0257 .

4.46. 3,3'-((3"-Bromo-4"'-hydroxy-5"'-methoxyphenyl)methylene)bis(6chloro-4-hydroxy-2H-chromen-2-one) (44)

White Solid; Yield: $87 \%$; M.p.: $282-284{ }^{\circ} \mathrm{C}$; ${ }^{1} \mathrm{H}$ NMR $(300 \mathrm{MHz}$, DMSO- $d_{6}$ ): $\delta 7.74$ (d, $J_{5,7 / 5^{\prime}, 7^{\prime}}=2.4 \mathrm{~Hz}, 2 \mathrm{H}, \mathrm{H}-5, \mathrm{H}-5^{\prime}$ ), 7.54 (dd, $J_{7,5}$, $\left.7^{\prime}, 5^{\prime}=2.4 \mathrm{~Hz}, \quad J_{7,8 / 7^{\prime}, 8^{\prime}}=6.3 \mathrm{~Hz}, \quad 2 \mathrm{H}, \quad \mathrm{H}-7, \quad \mathrm{H}-7^{\prime}\right), \quad 7.31$ (d, $J_{8,7 /}$ $8^{\prime}, 7^{\prime}=8.7 \mathrm{~Hz}, 2 \mathrm{H}, \mathrm{H}-8, \mathrm{H}-8^{\prime}$ ), 6.70 (bd.s, $1 \mathrm{H}, \mathrm{H}-6^{\prime \prime}$ ), 6.62 (bd.s, $1 \mathrm{H}, \mathrm{H}-$ $\left.2^{\prime \prime}\right), 6.13(\mathrm{~s}, 1 \mathrm{H},-\mathrm{CH}-), 3.58\left(\mathrm{~s}, 3 \mathrm{H}, \mathrm{OCH}_{3}\right) ;{ }^{13} \mathrm{C} \mathrm{NMR}(100 \mathrm{MHz}$, DMSO- $\left.d_{6}\right): \delta 166.1,166.1,163.8,163.8,150.9,150.9,148.1,141.4$, 133.4, 130.7, 130.7, 127.2, 127.2, 123.1, 123.1, 122.1, 121.0, 121.0, 117.7, 117.7, 110.2, 108.8, 103.9, 103.9, 56.0, 35.6; FAB (Neg.)-MS m/ $z=604[\mathrm{M}-\mathrm{H}]^{-1}, 606[\mathrm{M}+2-\mathrm{H}]^{-1} ;$ ESI-MS $m / z=604[\mathrm{M}+\mathrm{H}]^{+}, 606$ $[\mathrm{M}+2+\mathrm{H}]^{+} 608[\mathrm{M}+4+\mathrm{H}]_{;}^{+}$HRESI-MS Calcd for $\mathrm{C}_{26} \mathrm{H}_{16} \mathrm{BrCl}_{2} \mathrm{O}_{8}[\mathrm{M}$ $+\mathrm{H}]^{+}: m / z=604.9405$, Found 604.9448 .

\subsection{Urease inhibitory assay}

Urease (EC 3.5.1.5) enzyme solution $(25 \mu \mathrm{L})$ and $55 \mu \mathrm{L}$ buffers, containing $100 \mathrm{mM}$ urea, were incubated at $30^{\circ} \mathrm{C}$ for $15 \mathrm{~min}$ along with $5 \mu \mathrm{L}$ ( $1 \mathrm{mM}$ concentration) test compounds in 96-well plates. Ammonia production was measured in order to determine urease activity by utilizing the indophenols method by Weatherburn [25]. Briefly, $45 \mu \mathrm{L}$ phenol reagent ( $1 \% \mathrm{w} / \mathrm{v}$ phenol and $0.005 \% \mathrm{w} / \mathrm{v}$ sodium nitroprusside) and $70 \mu \mathrm{L}$ alkali reagent $(0.5 \% \mathrm{w} / \mathrm{v} \mathrm{NaOH}$ and $0.1 \%$ active chloride $\mathrm{NaOCl}$ ) were added to each well. By using a microplate reader (Spectra Max, Molecular Devices, USA), increase in absorbance was recorded at $630 \mathrm{~nm}$ after $50 \mathrm{~min}$. All reactions were carried out thrice in a final volume of $200 \mu \mathrm{L}$. The change in absorbance per min was processed by serving SoftMax Pro software (Molecular Devices, USA). All the assays were carried out at $\mathrm{pH} 8.2\left(0.01 \mathrm{M} \mathrm{K}_{2} \mathrm{HPO}_{4} \cdot 3 \mathrm{H}_{2} \mathrm{O}, 1 \mathrm{mM}\right.$ EDTA and $0.01 \mathrm{M} \mathrm{LiCl}$ ). Thiourea was used as the standard inhibitor of urease. Percentage inhibitions were calculated from the following formula:

$100-\left(\mathrm{OD}_{\text {testwell }} / \mathrm{OD}_{\text {control }}\right) \times 100$

\subsection{In vitro $B S A-M G$ Anti-glycation assay}

In this assay, BSA (Bovine serum albumin) of concentration (10 mg/ $\mathrm{mL})$ and $(14 \mathrm{mM})$ methylglyoxal were prepared in phosphate buffer $0.1 \mathrm{M}$ of $\mathrm{pH} 7.4$, containing $3 \mathrm{mM}$ sodium azide $\left(\mathrm{NaN}_{3}\right)$ which was used as antimicrobial agent. $1 \mathrm{mM}$ test compounds were dissolved in the DMSO. Assay was performed in triplicate. Reaction mixtures contained $50 \mu \mathrm{L}$ BSA, $50 \mu \mathrm{L}$ methylglyoxal, $20 \mu \mathrm{L}$ test compound, and $80 \mu \mathrm{L}$ phosphate buffer of $\mathrm{pH}$ 7.4. The reaction mixture was incubated for 9 days at $37^{\circ} \mathrm{C}$ under aseptic conditions. Fluorescence was recorded for excitation and emission at 330 , and $420 \mathrm{~nm}$ on a microtitre plate reader 
(Spectra Max M5, Molecular Devices, CA, USA) [30,31]. The percent inhibition of AGE formation was calculated by using the following formula:

$\%$ Inhibition

$=(1-$ Fluorescence of test sample/Fluorescence of the control $) \times 100$

The IC $_{50}$ values were determined at different concentrations $(1000-50 \mu \mathrm{M})$ of test compounds with the help of EZ-FIT Enzyme Kinetics Program (Perrella Scientific Inc., Amherst, USA). Rutin was used as a standard. In protein model system (BSA-MG glycation model), it showed an $\mathrm{IC}_{50}$ of $294 \pm 1.5 \mu \mathrm{M}$.

\subsection{9. $3 T 3$ cell based (mouse Fibroblast) cytotoxicity assay}

Standard MTT (3-[4,5-dimethylthiazole-2-yl]-2,5-dimethyltetrazolium bromide) colorimetric assay was used to evaluate the cytotoxicity of thirteen bis-coumarin derivatives with antiglycation properties in 96-well flat-bottomed microplates. $3 \mathrm{~T} 3$ Cells (mouse fibroblasts) in Dulbecco's modified eagle's medium was cultured for this purpose, supplemented with streptomycin, penicillin, and 5\% fetal bovine serum (FBS) by using a flask placed in a $5 \% \mathrm{CO}_{2}$ incubator at 37 ${ }^{\circ} \mathrm{C}$. The growth of cells was harvested exponentially by using hemocytometer, the harvested cells was counted and in a particular medium was diluted. Cell cultures was prepared with a required concentration and plated onto 96-well plates. After overnight incubation, medium was removed and fresh medium was added with different concentrations of the compound. After $72 \mathrm{~h}$, MTT was added to each well, and incubation was continued for $4 \mathrm{~h}$. Subsequently, $100 \mu \mathrm{L}$ of DMSO was added to each well to solubilize formazan-MTT adduct, formed by the action of enzyme mitochondrial dehydrogenase. The extent of MTT reduction to formazan within cells was calculated by measuring the absorbance at $540 \mathrm{~nm}$ by using a microplate ELISA reader [32].

\subsection{Statistical analysis}

All experiments were conducted using (SpectraMax M5, molecular Devices, CA. USA). Different softweres were used to analyze the results i.e (MS-Excel, SoftMaxPro 4.8, and GraphPad Prism-6.0). In the end $\mathrm{IC}_{50}$ values of active compounds were examined by using EZ-FIT, Enzyme kinetics software (Perrella Scientific, Inc., USA)

\section{Acknowledgement}

The authors are thankful to the Higher Education Commission (HEC), Pakistan, for providing financial support under "National Research Program for Universities", for Project No. 20-1910. One of us (Arsalan Nizamani) also acknowledges Higher Education Commission, Pakistan, for financial support through "Indigenous 5000 Scholarship Programme Batch-VII".

\section{Appendix A. Supplementary material}

Supplementary data to this article can be found online at https:// doi.org/10.1016/j.bioorg.2019.103170.

\section{References}

[1] K.P. Link, The anticoagulant 3, 3-methyl-bis-4-hydroxycoumarin, Federation Proc. 4 (1945) 176-182.

[2] P. Sengupta, M. Sen, P. Karuri, Structure of gerberinol novel dimethyldicoumarol from Gerbera lanuginosa benth, J. Indian Chem. Soc. 62 (1985) 916-919.

[3] K.M. Khan, F. Rahim, A. Wadood, N. Kosar, M. Taha, S. Lalani, A. Khan, M.I. Fakhri, M. Junaid, W. Rehman, M. Khan, S. Perveen, M. Sajid, M.I. Choudhary, Synthesis and molecular docking studies of potent $\alpha$-glucosidase inhibitors based on biscoumarin skeleton, Eur. J. Med. Chem. 81 (2014) 245-252.
[4] K.M. Khan, S. Iqbal, M.A. Lodhi, G.M. Maharvi, Z. Ullah, M.I. Choudhary, Atta-urRahman, S. Perveen, Bis-coumarin: new class of urease inhibitors; economical synthesis and activity, Bioorganic Med. Chem. 12 (2004) 1963-1968.

[5] M.I. Choudhary, N. Fatima, K.M. Khan, S. Jalil, S. Iqbal, Atta-ur-Rahman, New biscoumarin derivatives-cytotoxicity and enzyme inhibitory activities, Bioorg. Med. Chem. 14 (2006) 8066-8072.

[6] S.S. Li, Z. Gao, X. Feng, S.M. Hecht, Bis-coumarin derivatives from Edgeworthia gardneri that inhibit the lyase activity of DNA polymerase- $\beta$, J. Nat. Prod. 67 (2004) 1608-1610.

[7] H.A. Campbell, K.P. Link, The isolation and crystallization of the hemorrhagic agent, J. Biol. Chem. 138 (1941) 21-33.

[8] D. Witkowska, M. Rowinska-Zyrek, G. Valensin, H. Kozlovski, Specific poly-histidyl and poly-cysteil protein sites involved in $\mathrm{Ni}^{2+}$ homeostasis in Helicobacter pylori. Impact of $\mathrm{Bi}^{3+}$ ions on $\mathrm{Ni}^{2+}$ binding to proteins. Structural and thermodynamic aspects, Coord. Chem. Rev. 256 (2012) 133-148.

[9] L. Habala, A. Roller, M. Matuška, J. Valentová, A. Rompel, F. Devínsky, Complexes of $N$-hydroxyethyl- $N$-benzimidazolylmethylethylenediaminediacetic acid with copper(II) and cobalt(II): Preparation, crystal structure and urease inhibitory activity, Inorg. Chim. Acta 421 (2014) 423-426.

[10] B. Krajewska, I. Ureases, Functional, catalytic and kinetic properties: a review, J. Mol. Catal. B Enzym. 59 (2009) 9-21.

[11] H.L.T. Mobley, M.D. Island, R.P. Hausinger, Molecular biology of microbial ureases, Microbiol. Rev. 59 (1995) 451-480.

[12] H.L.T. Mobley, R.P. Hausinger, Microbial ureases: significance, regulation, and molecular characterization, Microbiol. Rev. 53 (1989) 85-108.

[13] K. Stingl, K. Altendorf, E.P. Bakker, Acid survival of Helicobacter pylori: how does urease activity trigger cytoplasmic pH homeostasis, Trends Microbiol. 10 (2002) $70-74$.

[14] S. Futagami, H. Takahashi, Y. Norose, K. Nagata, M. Kobayashi, T. Nomura, Analysis of immune response to Helicobacter pylori; identification of the protein recognized by anti-Helicobacter pylori antibodies from sera of patients with gastroduodenal diseases, Japanese Soc. Gastroenterol. 91 (1994) 2202-2213.

[15] T. Tanaka, M. Kawase, S. Tani, Urease inhibitory activity of simple $\alpha, \beta$-unsaturated ketones, Life Sci. 73 (2003) 2985-2990.

[16] Y.P. Xu, J. Qin, S.M. Sun, T.T. Liu, X.L. Zhang, S.S. Qian, H.L. Zhu, Synthesis, crystal structures, molecular docking and urease inhibitory, Inorg. Chim. Acta 423 (2014) $469-476$.

[17] J.M. Bremenr, Recent research on problems in the use of urea as a nitrogen fertilizer, Fertilizer Res. 42 (1995) 321-329.

[18] N. Ansari, Z. Rasheed, Non-enzymatic glycation of proteins: from diabetes to cancer, Biochem. (Moscow) Supplement Series B: Biomed. Chem. 3 (2009) $335-342$.

[19] H. Vlassara, M. Palace, Diabetes and advanced glycation endproducts, J. Intern. Med. 251 (2002) 87-101.

[20] S. Seo, S. Karboune, L. L' Hocine, V. Yaylayan, Characterization of glycated lysozyme with galactose, galactooligosaccharides and galactan: Effect of glycation on structural and functional properties of conjugates. LWT-Food, Sci. Technol. 53 (2013) 44-53.

[21] W. Li, H. Zheng, J. Bukuru, N. De Kimpe, Natural medicines used in the traditional Chinese medical system for therapy of diabetes mellitus, J. Ethnopharmacol. 92 (2004) 1-21.

[22] P. Ulrich, A. Cerami, Protein glycation, diabetes, and aging, Recent Prog. Horm. Res. 56 (2001) 1-51.

[23] S.J. Cho, G. Roman, F. Yeboah, Y. Konishi, The road to advanced glycation end products: a mechanistic perspective, Curr. Med. Chem. 14 (2007) 1653-1671.

[24] J.S. Ramkissoon, F.M. Mahomoodally, A. Nessar, H.A. Subratty, Natural inhibitors of advanced glycation end-products, Nutrit. Food Sci. 6 (2012) 397-404.

[25] M. Weatherburn, Phenol-hypochlorite reaction for determination of ammonia, Anal. Chem. 39 (1967) 971-974.

[26] M. Mercep, I. Malnar, B. Hrvacic, S. Markovic, A.F. Sucic, B. Bosnjak, A.C. Klonkay, R. Rupcic, A. Hutinec, I.J. Elenkov, Bis-(coumarin) compounds with antiinflammatory activity and their preparation, pharmaceutical compositions and use in the treatment of asthma and inflammatory diseases, PCT Int. Appl. (2006) WO 2006111858 A2 20061026.

[27] F. Li, J. Hu, J. Wang, Coumarin derivative as antioxidant and its preparation, Faming Zhuanli Shenqing (2014) CN 103601710 A 20140226.

[28] N. Hamdi, M.C. Puerta, P. Valerga, Synthesis, structure, antimicrobial and antioxidant investigations of dicoumarol and related compounds, Eur. J. Med. Chem. 43 (2008) 2541-2548.

[29] S. Muratovic, K. Duric, E. Veljovic, A. Osmanovic, D. Softic, D. Zavrsnik, Synthesis of bis-coumarin derivatives as antimicrobial agents, Asian J. Pharm. Clin. Res. 6 (2013) 131-134.

[30] M.I. Choudhary, A. Adhikari, S. Rasheed, B.P. Marasini, N. Hussain, W.A. Kaleem, Atta-ur-Rahman, Cyclopeptide alkaloids of Ziziphus oxyphylla Edgw as novel inhibitors of $\alpha$-glucosidase enzyme and protein glycation, Phytochem. Lett. 4 (2011) 404-406.

[31] C.H. Wu, G.C. Yen, Inhibitory effect of naturally occurring flavonoids on the formation of advanced glycation endproducts, J. Agric. Food. Chem. 53 (2005) 3167-3173.

[32] K. Dimas, C. Demetzos, M. Marsellos, R. Sotiriadou, M. Malamas, D. Kokkinopolos, Cytotoxic activity of labdane type diterpenes against human leukemic cell lines in vitro, Planta Med. 64 (1998) 208-211. 